\title{
EL LIDERAZGO POLÍTICO EN LA PRESIDENCIA DE FELIPE CALDERÓN (2006-2012)
}

José Luis MÉNDEZ

\section{INTRODUCGIÓN}

Desde el libro pionero de Neustadt, ${ }^{1}$ múltiples estudios muestran que los presidentes enfrentan un dilema: por un lado, para resolver los problemas nacionales en un contexto de dispersión política deben ejercer un liderazgo; por el otro, este es de naturaleza elusiva -difícil de definir y alcanzar- e implica tanto oportunidades como riesgos. Las concepciones tradicionales del liderazgo político han ocasionado que muchos presidentes se equivoquen al enfrentar este dilema y, a la vez, que muchos académicos y ciudadanos lo hagan al evaluarlos. Para esas concepciones, el liderazgo consiste en tener una "gran visión", transformar radicalmente un país o ser altamente carismático. Sin embargo, con frecuencia ello ha promovido la emergencia de presidentes demagógicos, así como evaluaciones descontextualizadas de gobernantes menos "atrayentes" pero más eficaces.

Este artículo busca argumentar que los gobernantes pueden afrontar más efectivamente el dilema arriba descrito, y los académicos y ciudadanos evaluarlos mejor, si conciben al liderazgo como "actuación estratégica". Para ello, primero se desarrolla teóricamente esta concepción y luego se presenta un análisis en ella basado en el gobierno de Felipe Calderón Hinojosa.

${ }^{1}$ Richard Neustadt, Presidential Power and the Modern Presidents: The Politics of Leadership from Roosevelt to Reagan, Nueva York, Free Press, 1990. 
Bajo la perspectiva propuesta, los gobernantes son evaluados en función de su contexto particular y no sólo en función de si son carismáticos, presentan una gran visión o incluso producen transformaciones profundas (que a veces no resultan principalmente de su actuación).

Así, existiría un liderazgo tanto cuando un presidente plantea una agenda ambiciosa ante un contexto que la exige y consigue realizarla gracias a una actuación estratégica -el caso más comúnmente asociado al liderazgo-, como cuando, ante un ámbito o coyuntura poco favorables para éste, actúa estratégicamente para obtener cambios importantes, aun cuando no sean radicales o novedosos (por consolidar por ejemplo cambios iniciados por su predecesor). No existiría liderazgo cuando, en un ámbito o coyuntura favorable al mismo, la actuación del gobernante no conduce hacia transformaciones profundas, ya sea porque no plantea la agenda ambiciosa que dicha coyuntura demanda o porque no actúa estratégicamente para concretarla (aun cuando dichas transformaciones pudieran llegar a suceder gracias a una causa distinta a la actuación presidencial, por ejemplo un boom económico externo o la acción de otros actores políticos). De esta manera, el liderazgo no sería un sinónimo exacto de logro.

Cuando se valora el grado de cambio obtenido en un país en función no sólo de su profundidad, sino también de las dificultades para conseguirlo, presidentes como Lincoln y Roosevelt en Estados Unidos o Juárez y Cárdenas en México permanecen como gobernantes que alcanzaron un alto grado de liderazgo; sin embargo, también se pueden incluir otros que han sido menos valorados. Para estos mismos dos países podríamos pensar por ejemplo en los casos de Truman o Ávila Camacho, respectivamente. ${ }^{2}$

${ }^{2}$ Probablemente esta consideración de Ávila Camacho sorprenderá a algunos lectores. Sin embargo, así como las medidas de redistribución social fueron muy importantes en el México profundamente desigual que Cárdenas encontró, las políticas más conciliadoras de su sucesor deben evaluarse en función del contexto altamente tensionado que heredó. En este sentido, muchos de sus logros fueron clave para la consecución de objetivos importantes para el país a unos años de la revolución, como la estabilidad política y el crecimiento económico (por ejemplo, la reconciliación política interna, la aceptación de la expropiación petro- 
En relación al carisma, aunque sin duda es un factor que puede ayudar a un gobernante a conseguir sus objetivos, no siempre se relaciona con el liderazgo: existen tanto casos de gobernantes con personalidades carismáticas que causaron decepción (por ejemplo, Fernando Collor en Brasil o Vicente Fox en México), como de presidentes personalmente menos "atrayentes" pero más eficaces (como Fernando Cardoso).

Podemos entonces concebir al liderazgo político como el logro de cambios importantes a través de una actuación estratégica, en función del contexto del gobernante. Aun cuando más objetiva y justa, esta noción involucra mayores dificultades teórico-metodológicas. ¿Cuándo es importante el cambio en una o varias políticas públicas? ¿Cuándo se debe a la actuación estratégica del gobernante? Ninguna de estas preguntas es fácil de contestar. Con todo, algunos autores han ya presentado opciones para concebir de manera más objetiva y sistemática el grado de cambio, ${ }^{3}$ cuya presencia se puede establecer hasta cierto punto de acuerdo a una combinación de indicadores (por mencionar algunos, índices de crecimiento económico o de desigualdad social, análisis especializados, encuestas, etc.).

lera por las compañías extranjeras, la reconstrucción de la infraestructura de comunicaciones y transportes, la creación del seguro social, el desplazamiento político de los militares, la apertura de vías institucionales para las clases medias, etc.). A diferencia de Truman, un presidente "sucesor" que en Estados Unidos ha sido más recientemente revalorado, Ávila Camacho permanece a la sombra de su predecesor. Rafael Loyola ("Manuel Ávila Camacho: el preámbulo del constructivismo revolucionario", en Will Fowler, coord., Gobernantes mexicanos, México, FCE, 2008, p. 211) ha señalado por ejemplo que "como lugar común, la administración del general Manuel Ávila Camacho es señalada por haber iniciado el entierro de las reformas cardenistas, por haber sofocado la movilización popular y su dinámica de reivindicaciones [...]. Empero [...] no significó un rompimiento con el gobierno predecesor; tampoco fue el régimen que inició el sofocamiento de la dinámica de reivindicaciones y de movilizaciones sociales. [...] No obstante, [...] ante la crudeza, las confrontaciones y el drama de los primeros regímenes pos-revolucionarios, se puede entender que el gobierno del denominado Presidente $\mathrm{Ca}$ ballero no despierte el mismo atractivo". Cursivas en el original.

${ }^{3}$ Peter Hall, "Policy Paradigms, Social Learning and the State: The Case of Economic Policymaking in Britain”, Comparative Politics, vol. 25, núm. 3, 1993, pp. 275-296. 
En cambio, en relación a la segunda pregunta, si bien existe una larga tradición en el estudio de la política que ha destacado la importancia del actor, la actuación estratégica no se ha desarrollado como una "variable" que pueda ser medida para realizar el estudio comparado de casos y relacionarla con el grado de cambio. En mi opinión, ello ha contribuido a que se subestime la importancia de esta tradición teórica del estudio de la política, sobre todo frente a los enfoques neo-institucionalistas. Por ello, en diversos textos he buscado precisar el significado de la acción estratégica de los ejecutivos (principalmente presidentes y gobernadores). ${ }^{4}$ A fin de poder evaluar el liderazgo presidencial de Felipe Calderón a continuación reseñaré brevemente estos elementos. ${ }^{5}$

\section{CONSIDERACIONES TEÓRICAS PARA EL ESTUDIO DEL LIDERAZGO POLÍTICO}

Concebido como actuación estratégica, el liderazgo político se compone de al menos tres elementos: un "posicionamiento pertinente", un "palanqueo inclusivo" e, indirectamente, un "estilo equilibrado".

El posicionamiento resulta de los problemas públicos que el gobernante decide incluir en su agenda prioritaria y la posición que se adopta ante ellos. Aunque por supuesto su contenido específico variará en función de cada situación particular, en términos generales este primer elemento de la actuación estratégica se podría definir como una suerte de "ambición realista"; esto es, aquélla que ante un contexto determinado permite reconocer tanto lo que se requiere como lo que se puede alcanzar, para, asumiendo

4 "Cincuenta años de estudios sobre el liderazgo presidencial: aportaciones para la consolidación democrática a través de una presidencia estratégica en América Latina”, Buen Gobierno, núm. 10, enero-junio de 2011. También: José Luis Méndez, "Estudio introductorio. El liderazgo político como actuación estratégica”, en José Luis Méndez (comp.), Liderazgo político, México, Siglo XXI, 2013.

${ }^{5}$ El lector podrá encontrar una exposición de dichos elementos más detallada y referida a algunos casos concretos en Méndez, "Estudio introductorio. El liderazgo político como actuación estratégica”. 
riesgos calculados, definir una agenda compuesta por objetivos importantes pero posibles.

En este aspecto, la visión más estratégica que Edwards desarrolla de varios presidentes estadounidenses del siglo xx es especialmente útil. ${ }^{6}$ Este autor señala por ejemplo que fijarse objetivos que bajo ciertos contextos son inalcanzables sólo llevará a "derrotas auto-inflingidas".

Edwards no hace un análisis contextual sistemático; tampoco toma en cuenta que, como "arte de lo posible", la política usualmente implica definir las metas a partir de "riesgos calculados", ya que de otra manera se pueden plantear objetivos poco importantes. Sin embargo, resulta muy útil su recomendación respecto a que el posicionamiento estratégico reconoce por ejemplo los asuntos en los que es posible alcanzar una mayoría legislativa y actúa "marginalmente" para obtenerla. También es útil retomar en este sentido a Neustadt, ${ }^{7}$ ya que en estos casos el gobernante estaría "pensando prospectivamente"; esto es, buscando obtener algunos triunfos iniciales para aumentar su capacidad política y plantear posteriormente una agenda de cambios adicionales. Esto involucraría entonces desarrollar una agenda menos ambiciosa en ámbitos o coyunturas desfavorables para el liderazgo, a fin de evitar derrotas anunciadas, así como una más ambiciosa en circunstancias favorables, de manera que se evite la decepción y consecuente reducción de la capacidad política del ejecutivo.

Un posicionamiento pertinente requiere, como se puede anticipar, una definición adecuada del contexto que el gobernante enfrenta. Aquí encontramos dificultades adicionales para el análisis del liderazgo como acción estratégica. Definir si un contexto político es favorable o desfavorable para el liderazgo no es una tarea fácil. Con todo, algunos esquemas nos ofrecen elementos iniciales para ello. Uno de ellos es el de Skowronek, quien define cuatro tipos de coyunturas en función de dos dimensiones: la vulnerabilidad del régimen a la crítica y el tipo de relación del gobernante

${ }^{6}$ George Edwards, III, The Strategic President: Persuasion and Opportunity in Presidential Leadership, Princeton, Princeton University Press, 2009.

${ }^{7}$ Op. cit. 
con su predecesor. ${ }^{8}$ Así, un tiempo político de "reconstrucción" es aquél en el que un presidente llega al gobierno como "opositor" y las circunstancias favorecen la promoción de cambios; por lo tanto resulta muy favorable para el liderazgo. El tiempo político opuesto es el que Skowronek llama de "desarticulación", en el que el gobernante llega como afiliado a un régimen en crisis. Dos tiempos intermedios en cuanto al grado de restricciones para el liderazgo son los que este autor denomina "preventivo" y "articulado".

Por supuesto, este esquema sólo puede ser un punto de partida. Con frecuencia es difícil definir una coyuntura como favorable o resistente al cambio; además puede haber otras dimensiones que se deben tomar en cuenta para definir el grado de restricciones del gobernante. Otro reto importante es identificar la medida en que una agenda es suficientemente ambiciosa pero no imposible de realizar. Además, dado que las circunstancias varían a lo largo de un gobierno, las agendas no pueden concebirse como estáticas. En todo caso, el punto central aquí es que el lugar donde el gobernante se coloca en términos de sus objetivos principales -y la medida en que dicho posicionamiento es adecuado al contexto que enfrenta- es un elemento que incide en forma fundamental sobre la medida en que su actuación será estratégica y que es susceptible de una evaluación objetiva y rigurosa, aunque no pueda ser siempre exacta. ${ }^{9}$

${ }^{8}$ Stephen Skowronek, The Politics Presidents Make: Leadership from John Adams to Bill Clinton, Cambridge, Harvard University, 1998.

${ }^{9}$ Como resulta obvio, se está adoptando aquí un enfoque contingente del liderazgo político. En las últimas décadas, en la ciencia política este enfoque ha sido adoptado por unos autores y criticado por otros. Las críticas suelen provenir de las dificultades para relacionar la acción con las circunstancias que la rodean. Pese a estas dificultades y los errores potenciales que pueden involucrar, en este y otros textos he argumentado que sí es posible evaluar la relación entre acción y contexto. Aunque por supuesto hay diferencias significativas entre el campo de la política y el de la guerra, en este último el posicionamiento -que alude al lugar en que un ejército se coloca al momento de una batalla (por ejemplo arriba o abajo de una colina)-, en general es considerado un elemento clave para evaluar el grado en que la acción militar se adecua al contexto. 
El segundo elemento de una presidencia estratégica es lo que he denominado un "palanqueo inclusivo", que permita impulsar la agenda del gobernante. Se utiliza este término porque la actuación estratégica en este ámbito se asocia con el uso combinado de los recursos políticos de manera que se aumente cualitativamente su potencia. ${ }^{10}$ Este "palanqueo" involucra varias dimensiones, por lo que la evaluación de la medida en la que se desarrolla depende de cada caso. Sin embargo, en este texto me referiré a dos aspectos que suelen ser importantes. El primero se relaciona con las maniobras políticas que inciden sobre el campo político de una manera tal que aumenta la fuerza relativa de un actor en relación a los demás. Se trata de acciones que cambian la correlación de fuerzas porque afectan por ejemplo el tipo y número de actores presentes en la arena política o el apoyo u oposición de estos hacia el gobernante. Aunque algunos autores han estudiado esta dimensión, ${ }^{11}$ la amplia variedad de situaciones que implica ha hecho difícil la reflexión sistemática en torno a la misma.

Un segundo aspecto tiene que ver más directamente con el uso de los recursos políticos con los que cuenta un gobernante en un régimen democrático para lograr que otros actores apoyen su agenda. Para entender mejor la forma en que se utilizan estos recursos, los he clasificado en tres grandes tipos: 1) "pasivos", porque no requieren de la acción directa sobre los actores, como por ejemplo la autoridad o el carisma; 2) "activos-suaves", que involucran una acción directa pero "suave" sobre los actores, como la influencia y la negociación; y, por último, 3) los "activos-duros", que involucran una acción directa y fuerte sobre los actores, como el poder y la fuerza, recursos que un Estado democrático puede

${ }^{10}$ Se refiere al uso de una viga como palanca. Al contrario de leveraging, bastante utilizado en el idioma inglés, "palanqueo" es un término correcto pero inusual en español. Sin embargo, es el único que mantiene un significado relacionado con una combinación de varios recursos para potenciar la fuerza individual que cada uno de ellos tiene. Un término cercano es el de "maniobra”, pero, a diferencia del anterior, denota en menor medida una acción y a veces adquiere en español un sentido más negativo.

${ }^{11}$ William H. Riker, The Art of Political Manipulation, New Haven, Yale University Press, 1986. 
utilizar en forma legal y legítima bajo ciertas restricciones y condiciones (por ejemplo, en contra del crimen organizado). ${ }^{12}$

Como en el posicionamiento, sería un error pensar que existen recetas para una combinación efectiva de los recursos políticos, ya que ésta es altamente contingente respecto a una amplia variedad de contextos. Con todo, al respecto he hecho dos planteamientos. Por un lado, en las democracias los recursos pasivos y activos-suaves son más adecuados. Así, de un liderazgo democrático se esperaría una mayor utilización de los recursos como los de la autoridad, la negociación y sobre todo la influencia, que permiten incluir o convencer a más actores. No obstante, si bien en general el uso de cualquier recurso ofrece oportunidades y riesgos, por otro lado el consejo de Maquiavelo es pertinente: la combinación de diversos tipos de recursos tenderá a ser más efectiva que la utilización de sólo uno de ellos. La reducción del crimen por ejemplo puede atacarse tanto con el poder y la fuerza como con políticas sociales.

${ }^{12}$ El palanqueo a partir de los recursos políticos es una operación compleja, que ofrece tanto oportunidades como riesgos. El primero que lo estudió en forma sistemática fue Maquiavelo, quien presentó su conocida recomendación al príncipe: ser a la vez un zorro y un león (Nicolás Maquiavelo, The Prince, Cambridge, Cambridge University Press, 1989, pp. 61-63). Gramsci (Notas sobre Maquiavelo, sobre política y sobre el Estado moderno, México, Juan Pablos, 1975, p. 6) retomó esta metáfora cuando habló de "la doble naturaleza del centauro maquiavélico, de la bestia y el hombre, de la fuerza y el consenso, de la autoridad y de la hegemonía”, para, sin descartar el uso de los primeros, destacar la mayor efectividad de los segundos en el Estado moderno. No obstante, recientemente Nye (Presidential Power and the Modern Presidents: The Politics of Leadership from Roosevelt to Reagan, Nueva York, Oxford University Press, 2008) también retomó la imagen de Maquiavelo para diferenciar entre "poder suave" y "poder duro" y concluir que el "poder inteligente" es aquél que involucra a ambos (Rockman lo denomina "liderazgo inteligente". Rockman, "When It Comes to Presidential Leadership, Accentuate the Positive but Do Not Forget the Normative", en Bert Rockman y Richard Waterman, eds., Presidential Leadership: The Vortex of Power, Oxford, Oxford University Press, 2008). En esta concepción, el palanqueo efectivo involucraría entonces la combinación de recursos pasivos o activos-suaves con recursos activos-duros (como por ejemplo la influencia y la negociación con el poder). Una discusión más extensa sobre la clasificación y uso de los recursos políticos se puede encontrar en Méndez, "Estudio introductorio. El liderazgo político como actuación estratégica". 
En función de lo anterior, el liderazgo se podría definir entonces con más precisión como la obtención de cambios (importantes o radicales, dependiendo del contexto) a partir de un posicionamiento pertinente y un palanqueo inclusivo. No obstante, podemos hablar de un tercer componente del liderazgo, aunque más bien indirecto ya que es el que permite o facilita la emergencia de sus dos primeros elementos: la capacidad decisoria (a la que algunos autores se han referido como "buen juicio"13). Este elemento se encuentra en un ámbito diferente, el del estilo de toma de decisiones, igualmente o incluso quizá aún más complejo que el de la acción política. Es un elemento difícil de evaluar (y de obtener), tanto porque involucra diversos factores, ${ }^{14}$ como porque, paradójicamente, varios de ellos son opuestos. Aquí me limitaré a señalar dos factores de cuyo equilibrio la capacidad decisoria tiende a emerger: la apertura y la determinación. La primera le permite a los gobernantes abrirse al diálogo y a distintos puntos de vista; y con ello, una capacidad tanto para "calibrar" adecuadamente las decisiones, como para fiscalizar sus resultados, y, en su caso, reconocer y corregir los errores. Por su parte, la determinación les permite enfrentar los asuntos y tomar las decisiones oportunamente, así como mantenerlas e impulsarlas aun cuando puedan existir resistencias.

A partir de esta definición es posible hablar de dos "estilos personales de gobernar": un estilo "equilibrado", que balancea la apertura con la determinación -la consideración de diversas alternativas con la firmeza en las decisiones-, y un estilo "desequilibrado”, que cae ya sea en el extremo de la discusión caótica, vacilante y negligente, o en el del voluntarismo hermético, arrogante e intransigente. Maquiavelo decía en El príncipe que dependiendo del contexto tanto la cautela como la impetuosidad pueden ser efectivos. ${ }^{15}$ Sin embargo, es posible decir que, en general, el primer estilo

${ }^{13}$ Nannerl O. Keohane, Thinking about Leadership, Princeton, Princeton University Press, 2010.

14 T. Preston y M. G. Hermann, "Presidential Leadership Style and the Foreign Policy Advisory Process”, en E. R.Witkopf y J. M. McCormick (eds.), The Domestic Sources of American Foreign Policy: Insights and Evidence, Landham, Rowman y Littlefield, 2004.

${ }^{15}$ Maquiavelo, op. cit., pp. 85-87. 
facilitará el posicionamiento y palanqueo estratégicos, mientras que el segundo los dificultará. ${ }^{16}$

Aunque los dos elementos de la capacidad decisoria son importantes, por el tipo de personalidad de quienes suelen llegar a puestos como la presidencia o la gubernatura (y por la naturaleza propia de los mismos), debe subrayarse que el primero de ellos es quizá el más difícil de obtener. En general, los gobernantes tienden a caer con facilidad en la arrogancia o la excesiva confianza, ${ }^{17}$ un riesgo que paradójicamente puede ser incluso mayor cuando un gobernante piensa que está siendo "estratégico". ${ }^{18}$

En este sentido, he mencionado que no siempre a la tarea de formular las políticas le siguen necesaria o únicamente las de coordinar y ejecutar. De hecho, muchos de los problemas públicos representan "problemas perversos", ante los cuales tenemos que asumir posiciones más "modestas" y estrategias de acierto-error que posiciones iniciales definitivas (por más que se basen en sofisticados cálculos). Así, muchas de las políticas pronto se convierten en "blancos en movimiento" 19 porque su implementación se

${ }^{16}$ Daniel Cosío Villegas realizó un estudio pionero del estilo de gobernar ( $E l$ estilo personal de gobernar, México, Grijalbo, 1972). Utilizando un enfoque parecido, Krauze realizó un estudio de los presidentes mexicanos del siglo xx (La presidencia imperial, México, Tusquets, 2004). Sin embargo, estos análisis resaltaron en forma más bien casuística o anecdótica la relación entre los atributos personales y la actuación política, sin desarrollar la toma de decisiones como una variable que permita un análisis comparativo riguroso. Estos forman parte de un amplio conjunto de estudios que analizan rasgos de la personalidad de los gobernantes y que entran entonces en el complejo campo de la psicología. Los conceptos de apertura y determinación pueden relacionarse con algunos rasgos de la personalidad, pero no buscan explorarla; más bien se refieren a ciertas acciones que definen la manera predominante en que el gobernante toma decisiones, como si dialogase con otros actores sin por ello retrasarlas excesivamente.

${ }^{17}$ Robert Dallek, "When Presidents Become Weak", en Walter Isaacson (ed.), Profiles in Leadership: Historians on the Elusive Quality of Greatness, Nueva York, W.W. Norton \& Company, 2010.

18 Richard M. Pious, Why Presidents Fail, Nueva York, Rowman and Littlefield Publishers Inc., 2008.

${ }^{19}$ José Luis Méndez, "La política pública como variable dependiente: hacia un análisis más integral de las políticas públicas”, Foro Internacional, enero-marzo de 1993. 
convierte más bien en su reformulación. Cuando se ve desde el mirador de una oficina presidencial, el gobierno se presenta en realidad como una combinación abigarrada, interdependiente y bastante impredecible de procesos múltiples, en los que la incertidumbre y la posibilidad de error siempre están presentes. Por ello, desde hace cerca de una década he insistido en que, más que un lugar únicamente para la acción, la presidencia es un lugar en el que constantemente se tienen que estar evaluando y decidiendo los ámbitos y los tiempos tanto para la acción como para la abstención, la resistencia o la corrección. ${ }^{20}$ Aunque no hay recetas para ello, el destino de una administración se finca en buena medida en el acierto y oportunidad estratégicos con que se toman las decisiones sobre estos ámbitos y tiempos.

En síntesis, existe una suerte de cadena de elementos que conducen al liderazgo político, la cual termina en el cambio importante (moderado o radical), pasa por posicionamiento pertinente y el palanqueo inclusivo, e inicia en el estilo decisorio equilibrado. En función de ello, podríamos concordar en que, ante la abundancia de estudios que enfatizan en forma anecdótica y asistemática el "estilo personal de gobernar", es importante estar conscientes de que la estructura institucional y el contexto histórico son factores muy importantes. ${ }^{21} \mathrm{~A}$ la vez, debemos también reconocer que estos últimos básicamente constituyen marcos que facilitan o dificultan el ejercicio político y que el factor que incide de manera más directa y precisa en la evolución de un gobierno -y hasta cierto punto de una nación- son las decisiones de los gobernantes, y más específicamente la medida en que éstas son estratégicas. Ello permite entender por ejemplo la variación tan amplia que existe en los logros de los gobernantes que han

${ }^{20}$ José Luis Méndez, "La Oficina de la Presidencia en los gobiernos de América Latina", ponencia presentada en el CLAD, Santiago de Chile, 2005. También: "La oficina presidencial y el liderazgo político en México y Estados Unidos ¿incertidumbre competitiva o certidumbre cooperativa?", Foro Internacional, octubre-diciembre de 2007.

${ }^{21}$ Soledad Loaeza, "El estilo personal de Vicente Fox y los límites de la autoridad presidencial", en Soledad Loaeza, Acción Nacional. El apetito y las responsabilidades del triunfo, México, El Colegio de México, 2010. 
actuado bajo estructuras constitucionales y coyunturas políticas similares. ${ }^{22}$

\section{ANTECEDENTES y CONTEXTO DE LA PRESIDENCiA DE Felipe Calderón Hinojosa}

Felipe Calderón llegó a la presidencia relativamente joven (nació en 1962, en Morelia, Michoacán). Sin embargo, contaba con una considerable experiencia política, alguna experiencia directivo-administrativa y una buena preparación académica. Hijo de una de las familias fundadoras del Partido Acción Nacional (PAN), desde muy joven tuvo una militancia activa en ese partido político, del que llegó a ser presidente entre 1996 y 1999. Además de su experiencia político-partidista, tuvo también una amplia experiencia legislativa, ya que fue diputado local en el Distrito Federal (19881991) y diputado federal (1991-1994; 2000-2003), por lo que podía esperarse que tendría la alta capacidad de persuasión y negociación políticas. Sólo tenía poca experiencia en funciones directivoadministrativas, ya que únicamente se había desempeñado como Director General de Banobras durante 2003 y secretario de Energía durante 2004. ${ }^{23}$ Obtuvo una licenciatura en derecho en la Escuela Libre de Derecho, una maestría en economía en el ITAM y otra en administración pública en la Escuela Kennedy de Harvard.

Durante 2005 y 2006, Calderón y su equipo mostraron una alta capacidad estratégica, gracias a la cual remontaron varias situaciones adversas. Primero, con todo y que no era apoyado por el presidente en funciones -Vicente Fox, también del PAN-, Calderón logró imponerse como el candidato panista a la presidencia. Posteriormente, cuando en la campaña electoral se encontraba bastante

${ }^{22}$ Para una discusión inicial de esta variación en los resultados de varios presidentes de América y su relación con la capacidad decisoria, puede verse Méndez, "Estudio introductorio. El liderazgo político como actuación estratégica".

${ }^{23}$ Puesto al que renunció inmediatamente después de que el entonces presidente Vicente Fox lo criticara públicamente por estar en un acto en el que se lanzaba su campaña para la presidencia cuando aún faltaban cerca de veinte meses para el inicio del año electoral. 
lejano del candidato puntero -Andrés Manuel López Obrador, del Partido de la Revolución Democrática (PRD)-, remontó la diferencia presentando a éste como un "peligro para México" y a sí mismo como la opción de certidumbre, estabilidad y "empleo" (a lo que López Obrador ayudó ignorando por varios meses la fuerte campaña publicitaria en su contra).

Como es sabido, las autoridades electorales dictaminaron que ganó la presidencia, aunque con una diferencia de muy pocos votos $(0.58 \%$, equivalente a cerca de 250000 votos $)$, lo cual llevaría a López Obrador a cuestionar la elección. Pese a ello, y a que los legisladores del PRD trataron físicamente de impedírselo, Calderón tomó la protesta de ley en diciembre de 2006.

Como se planteó en la sección anterior, para evaluar en forma más objetiva y justa el grado de liderazgo político de un gobernante, debemos considerar su contexto. ¿Cómo se puede calificar en este sentido el "tiempo político" de Felipe Calderón? Un primer análisis, limitado a las dos dimensiones mencionadas por Skowronek, llevaría a argumentar que enfrentaba una coyuntura de "articulación”, la cual, por lo tanto, involucraba un contexto a la vez favorable y desfavorable para ejercer un liderazgo. Sin embargo, conviene tomar este marco como un punto de partida para analizar con mayor precisión la coyuntura de cada gobernante.

En cuanto a la dimensión de la relación con el presidente anterior, Calderón enfrentaba una circunstancia desfavorable, porque, con todo y sus diferencias con Fox, llegaba al poder como un presidente "afiliado": pertenecía al PAN y había desarrollado una campaña basándose en la ideología de este partido y en los logros de su antecesor. No tenía entonces mucho margen para presentar propuestas novedosas y, como todos los gobernantes afiliados, enfrentaba el riesgo de ser percibido como una mera "sombra" de otro gobernante.

En cuanto a la segunda dimensión, cabe preguntarse: ¿podían los compromisos asumidos por el presidente anterior proveer todavía soluciones creíbles a los problemas del momento o eran vulnerables a acusaciones de ineficacia? En este sentido, sin duda debe tomarse en cuenta que un importante sector de la población había apoyado la posición de outsider favorable a la justicia social 
de López Obrador; además, al menos una parte de ese sector no consideraba que la victoria de Calderón hubiera sido legítima. Sin embargo, por otro lado, Fox no terminaba con bajos índices de popularidad (rondaba $60 \%$, que no es bajo para los estándares mexicanos) y, al menos originalmente, él y su partido habían también abanderado propuestas dirigidas a establecer un "nuevo orden”. Además, muchas de estas propuestas no se habían logrado realizar, lo que le abría a Calderón la posibilidad no sólo de ser un "innovador ortodoxo" (en los términos de Skowronek), sino de ser uno activo, que se puede distanciar de un predecesor que buscó ser "reconstructor" pero que no tuvo éxito en ello. En este sentido, no enfrentaba una circunstancia tan difícil para el liderazgo como la que enfrentaron en Estados Unidos presidentes afiliados como James Madison, Martin Van Buren o Harry S. Truman, que habían sucedido a presidentes que terminaron sus periodos como reformadores exitosos.

En otras palabras, si bien ya no podía proponer el "nuevo orden" que la sociedad había demandado con la elección de Fox, Calderón tenía amplias posibilidades para evitar ser un mero "consolidador" y erigirse más bien como el verdadero "constructor" de ese "nuevo orden", llevando a cabo las múltiples reformas que Fox había prometido pero fallado en alcanzar (fiscal, pensionaria, energética, electoral, laboral, educativa, de seguridad, de telecomunicaciones, etc.).

Las posibilidades presidenciales para erigirse en líder político deben ser adicionalmente consideradas en función de al menos otros dos elementos que no están presentes en el esquema de Skowronek: la correlación de fuerzas en el congreso y la reputación inicial del presidente. Respecto a la primera, observamos una situación particular: Calderón había ganado la presidencia con un escaso margen, pero su partido había obtenido 206 diputaciones, sólo una menos que Vicente Fox al inicio de su sexenio. No tenía entonces mayoría en esa cámara, pero tampoco estaba muy lejano de ella, lo que le daba un importante margen de maniobra para ejercer cierto liderazgo legislativo; además, había desarrollado una campaña enfilada contra el PRD, no contra el PRI, con cuyos 106 diputados podía formar una mayoría. En el Senado, el PAN 
contaba con 52 senadores y el PRI con 33, que juntos sumaban 85 de 128. Además, como en 2000-2003, el PRI no estaba unificado en esos momentos alrededor de una figura fuerte; de hecho, su desprestigiado candidato presidencial había quedado en un lejano tercer lugar, lo que le abría al presidente posibilidades adicionales para una negociación fructífera con este partido. ${ }^{24}$

El segundo aspecto, la reputación presidencial, es importante para evaluar las posibilidades del liderazgo porque representa una fuente esencial del capital político de todo gobernante, ya que incide sobre la disposición de los demás actores políticos para apoyar o atacar sus iniciativas. Fox por ejemplo contaba al inicio de su administración con un comparativamente alto porcentaje de aceptación de $70 \%$. Es significativo notar en este sentido que para noviembre de 2006 el porcentaje de Calderón no era mucho más bajo: se ubicaba en un importante $64 \% .^{25}$

${ }^{24}$ Es cierto que el entonces presidente del PAN, Manuel Espino, no era particularmente afín al presidente y que este partido sólo había ganado las elecciones para gobernador en 6 de las 32 entidades federativas. Sin embargo, ante un presidente de su propio partido que iniciaba su administración, Espino no tenía en realidad mucha capacidad de movimiento (como de hecho se vería más adelante), mientras que el apoyo de los gobernadores -aunque importante sobre todo para la ejecución de políticas públicas y la realización de cambios constitucionales- no era tan definitorio en el ámbito legislativo, donde las dirigencias partidarias jugaban un papel fundamental. Si bien no fue producto de una coalición electoral, la posibilidad de desarrollar una coalición legislativa mayoritaria más o menos permanente está dentro del margen de decisión de los presidentes mexicanos, como lo demostraría el presidente que sucedió a Calderón.

${ }^{25}$ Consulta Mitofsky, "México: Evaluación Final de Gobierno Felipe Calderón: 2006-2012”, 2012, http://consulta.mx/web/images/evgobierno/2013/evaluacion finalcalderon.pdf Aunque este porcentaje se puede explicar por varios factores, aquí podemos mencionar al menos dos. Por un lado, López Obrador había ocupado por varias semanas un tramo de la avenida Reforma de la ciudad de México; con ello cometió un (segundo) error estratégico: para fines de año su imagen se había deteriorado considerablemente y había tenido que desocupar la avenida sin haber conseguido revertir el triunfo de su opositor. En contraste, el candidato electo mostraba una imagen de tolerancia y ecuanimidad a la vez que de seriedad y respeto hacia la institución presidencial, distanciándose con ello tanto de la reputación radical de su principal contendiente en las elecciones como de la imagen superficial y descuidada que Fox se había labrado. 
En síntesis, si analizamos conjuntamente estas cuatro dimensiones -relación con su predecesor, eficacia de la propuesta gubernamental asumida, correlación de fuerzas legislativas y reputación presidencial-, podemos observar que Calderón tenía un importante margen para ejercer un liderazgo político. Más específicamente, podía elegir de entre una amplia variedad de reformas para erigirse en el impulsor del "nuevo orden" que había venido proponiendo su antecesor y su partido, a partir de una mayoría legislativa que era alcanzable a partir de la representación obtenida por el PAN, las condiciones del PRI después de la elección y el nivel de aceptación presidencial.

Definidas las posibilidades ofrecidas por su contexto, pasaremos ahora a analizar el grado de liderazgo obtenido por Calderón, en función de los primeros dos elementos del marco analítico propuesto: el posicionamiento pertinente y el palanqueo inclusivo. El análisis se dividirá en dos periodos: de la elección en julio de 2006 a diciembre de 2009 y de esta fecha al final del sexenio. Como en función del marco analítico es fundamental analizar el grado en que las decisiones del presidente le abrieron o cerraron margen de maniobra para ganar capital político en el mediano plazo, me enfocaré en la evolución en los primeros tres años de las políticas más significativas desde este punto de vista.

2006-2009: DE LA RECUPERACIÓN INICIAL AL PRINCIPIO DEL DECLIVE

Ganada la elección en julio de 2006, las dos tareas principales por realizar eran la conformación del gabinete y la definición de la "agenda de salida" del gobierno. Respecto al primer tema, el 7 de septiembre el presidente declaró que si la integración del gabinete ayudaba a conformar una mayoría en el congreso probablemente integraría a expriistas. ${ }^{26}$ De acuerdo a Núñez, ${ }^{27}$ Calderón

${ }^{26}$ El Universal, 7 de septiembre de 2006.

${ }^{27}$ Ernesto Núñez, Crónica de un sexenio fallido: la tragedia del calderonismo, México, Grijalbo, 2012, p. 39. 
incluso se refirió a la posibilidad de un gobierno de coalición con los partidos que quisieran sumarse. También había dicho -tanto antes $^{28}$ como después de ganar las elecciones- que él haría "política al nivel de cancha; en otras palabras, que él sí buscaría reunirse personalmente con los legisladores. Estas declaraciones hacen suponer que, al menos al principio, era consciente de que para aprobar reformas era necesario negociar directamente con los diputados y concederle espacios en el gobierno a la oposición (principalmente al PRI, dado el rompimiento con el PRD).

Es posible argumentar que México ha tenido lo que llamaría un "presidencialismo de partido", diferente tanto al "presidencialismo de coalición" 29 de países como Brasil como al "presidencialismo de un partido", como el que se puede dar en los Estados Unidos. Esto es, por un lado, que no se han formado gabinetes multipartidistas compuestos por miembros de los partidos que conforman una coalición parlamentaria (que usualmente viene de una coalición electoral) y, por el otro, que dichos gabinetes tampoco se han formado tomando en cuenta a un congreso poderoso, con importantes facultades para intervenir en el nombramiento y vigilancia de los secretarios y sus ministerios, y donde el presidente ha tendido a estar constantemente negociando con dicho congreso (e incluso con sus propios secretarios y la burocracia). En México, aunque no todos los secretarios sean necesariamente del partido del presidente, el presidente ha gobernado claramente basándose en su partido y en un gabinete que puede nombrar sin mayores restricciones y que en consecuencia le ha sido muy cercano. Ello no quiere decir, sin embargo, que no pueda desarrollar una coalición de varios partidos en el congreso alrededor de una agenda común (especialmente si enfrenta una coyuntura de reconstrucción en el contexto de un gobierno dividido).

No obstante lo anterior, los hechos pronto mostrarían la falta de voluntad del presidente electo para conformar una coalición gubernamental o al menos acordar una agenda común en forma

${ }^{28}$ El Universal, 26 de noviembre de 2012.

${ }^{29}$ Sérgio Abranches, "O presidencialismo de coalizão: o dilema institucional brasileiro”, Dados, vol. 31, num. 1, 1988, pp. 5-33. 
pública. En septiembre, por ejemplo, envió a los partidos un documento un tanto contradictorio: por un lado, llamaba a que la agenda nacional se elaborara con la participación de todos los partidos, pero, por el otro, desglosaba lo que sería la agenda de su gobierno (una ambivalencia que se manifestaría en varios momentos a lo largo del sexenio). En diciembre de 2006 se conocieron los integrantes tanto del gabinete como de la presidencia: todos eran muy cercanos al presidente electo. Si bien entre ellos se encontraban expriistas -Javier Lozano, nombrado para la Secretaría del Trabajo, y Tomás Ruiz, un exfuncionario del gobierno de Ernesto Zedillo, nombrado para la Secretaría de Comunicaciones y Transportes-, ninguno de ellos era visto por el PRI como un interlocutor partidista. La coordinación de la Oficina de la Presidencia recaería en su colaborador más cercano, Juan Camilo Mouriño, quien, como discutiremos más adelante, desarrollaría un estilo decisorio altamente centralizado.

Además, el gabinete tuvo en general un muy bajo perfil, al conformarse principalmente por funcionarios poco conocidos a nivel nacional y con poca experiencia político-administrativa (un rasgo que se acentuó conforme avanzaba el sexenio). Una excepción a ese bajo perfil general fue Agustín Carstens -en quien recayó el nombramiento de Secretario de Hacienda y Crédito Público-, un funcionario con amplia experiencia nacional e internacional en el ámbito financiero. Otra excepción fue Josefina Vázquez Mota, quien había fungido como Secretaria de Desarrollo Social durante la presidencia de Vicente Fox y que ahora fue designada como Secretaria de Educación Pública (sin embargo, en este caso el presidente hizo al mismo tiempo una sorprendente designación: nombró como Subsecretario de Educación Básica a Fernando González, nada menos que el yerno de la lideresa del Sindicato Nacional de Trabajadores de la Educación (SNTE), Elba Esther Gordillo). Como secretario de Gobernación nombró a Francisco Ramírez Acuña, exgobernador panista de Jalisco, quien empero tenía poco peso en la clase política nacional (aunque había sido uno de los organizadores del lanzamiento adelantado de campaña por el que Vicente Fox había criticado al ahora presidente). Por desgracia, un gabinete y un staff presidencial de amigos y funcionarios de bajo 
perfil, difícilmente dispuestos a contradecir al jefe del Ejecutivo, no sería de mucha ayuda en los momentos de las decisiones estratégicas más difíciles. ${ }^{30}$

La segunda tarea a desarrollar durante el periodo de transición de gobierno era la definición de la agenda con la que el gobierno iniciaría. Como planteamos en la sección anterior, una agenda estratégica es aquella que, de acuerdo al contexto, plantea objetivos ambiciosos pero factibles a la vez. Además, siguiendo a Neustadt, es una agenda "prospectiva", esto es, que permite resolver problemas existentes al inicio del gobierno pero también abrir margen de maniobra y aumentar el capital político en los años subsecuentes.

Por la rapidez y dimensión de sus acciones en este tema, así como por el lugar destacado del mismo en su agenda de eventos y en sus discursos, desde los primeros días de su gobierno Calderón dejó muy claro lo que sería su principal objetivo: la "batalla" contra el crimen organizado, especialmente el relacionado con el narcotráfico. Varios hechos muestran que tomó esta decisión durante el periodo de transición. Por ejemplo, en septiembre el entonces candidato electo había ya visitado Michoacán, donde al parecer el entonces gobernador Lázaro Cárdenas Batel le había informado que había solicitado sin éxito al presidente Fox la intervención federal, y donde declaró que combatiría firmemente al crimen organizado. El mes siguiente había visitado Colombia y conocido de cerca la estrategia que se había seguido ahí para combatir la violencia y los buenos réditos políticos que ello le estaba produciendo al presidente Uribe. Asimismo, en México las encuestas ya señalaban en ese entonces que el tema era importante para la población, lo que de acuerdo a un entrevistado le hizo pensar que atenderlo podría también aumentar su popularidad. ${ }^{31}$ Cuando en noviembre visitó Washington, D. C., señaló que la seguridad sería también una nueva prioridad de la agenda bilateral.

${ }^{30}$ Un ejemplo opuesto es el del gabinete de Lincoln, quien tuvo la seguridad personal y la capacidad política suficientes para nombrar y dirigir a un "equipo de rivales", lo que le permitió sortear los complejos dilemas ofrecidos por la guerra civil estadounidense (Doris Kearns Goodwin, A Team of Rivals: The Political Genius of Abraham Lincoln, Nueva York, Simon \& Schuster, 2005).

${ }^{31}$ Entrevista a funcionario público, México, D. F., 23 de noviembre de 2010. 
En función de lo anterior, el primer tema que tocó en su discurso de toma de posesión fue el de la inseguridad, respecto a la cual señaló:

Hoy la delincuencia pretende atemorizar e inmovilizar a la sociedad y al Gobierno; la inseguridad pública amenaza a todos y se ha convertido en el principal problema de estados, ciudades y regiones enteras [...]. Sé que restablecer la seguridad no será fácil ni rápido, que tomará tiempo, que costará mucho dinero, e incluso y por desgracia, vidas humanas. Pero ténganlo por seguro, esta es una batalla en la que yo estaré al frente, es una batalla que tenemos que librar y que unidos los mexicanos vamos a ganar a la delincuencia. ${ }^{32}$

En las semanas siguientes, el presidente puso en marcha una operación conjunta en Michoacán que involucró la movilización a ese estado de más de 5000 efectivos de las fuerzas federales, principalmente del ejército pero también de la Fuerza Aérea, la Marina, la Secretaría de Seguridad Pública y la Procuraduría General de la República, acompañados por decenas de aviones y helicópteros y cientos de vehículos militares terrestres. Puesto en marcha el operativo, el 3 de enero de 2007 Calderón visitó ese estado. Ataviado con una gorra y chamarra militares, ${ }^{33}$ el presidente se refirió de nuevo a la "batalla" y el "combate" contra el crimen organizado. De manera similar, durante los primeros meses de ese año se lanzaron operativos militares conjuntos en Baja California, Guerrero, Nuevo León, Tamaulipas, Veracruz y Chihuahua, acompañados por fuertes discursos contra la delincuencia y anuncios de capturas de narcotraficantes. ${ }^{34}$ En marzo de 2007, el Ejecutivo envió al Senado una iniciativa de reforma constitucional en materia de

${ }^{32}$ Felipe Calderón, Mensaje del Primer Informe de Gobierno, México, Presidencia de la República, 2006.

${ }^{33}$ Las cuales le quedaban visiblemente grandes, lo que daría pie a múltiples caricaturas que mostraban un escepticismo respecto a la capacidad del presidente para afrontar este problema.

${ }^{34}$ Un indicador de la centralidad del tema del crimen organizado en la agenda son las referencias constantes al mismo por parte del presidente aun en los discursos de eventos relacionados con otros temas. 
seguridad y justicia, para elevar las capacidades persecutorias del Estado mediante la aplicación de medidas cautelares como el arraigo y los cateos, así como la ampliación de las facultades de investigación de las policías. ${ }^{35}$

Aunque la denominada "guerra" para derrotar al "enemigo" del narcotráfico era claramente su objetivo central, la agenda gubernamental de Calderón incluyó otras metas importantes en los primeros meses. Estas fueron, principalmente, una reforma del sistema de pensiones del gobierno federal, que se encontraba en una crisis financiera, una reforma fiscal, que ampliara el reducido margen de maniobra presupuestal del Estado, y una reforma electoral, que atendiera a la crisis que se había generado tras la elección de julio.

Entre marzo y septiembre de 2007, el presidente obtuvo varios logros en estos temas. Primero la aprobación en marzo de la reforma a la Ley del issste, que permitió la individualización de las cuentas de los derechohabientes, lo que -se argumentó- permitiría la sustentabilidad en el largo plazo de ese sistema pensionario. En septiembre se aprobó una reforma fiscal que sustituyó el Impuesto al Activo (IMPAC), con el Impuesto Empresarial a Tasa Única (IETU), así como el Impuesto a los Depósitos en Efectivo (IDE), con lo que se aumentó parcialmente el ingreso tributario. Ese mismo mes, el Senado aprobó la reforma electoral, por la cual se renovaría escalonadamente el Consejo General del Ife y se le encargaría a este instituto la asignación de la propaganda electoral. A su vez, el Plan Nacional de Desarrollo 2007-2012 había sido presentado en mayo (cuyo primer eje era el de "Estado de Derecho y Seguridad", seguido por "Economía Competitiva y Generadora de Empleo", "Igualdad de Oportunidades", "Sustentabilidad Ambiental”36 y, al final, "Democracia Efectiva y Política Exterior Responsable”).

${ }^{35}$ Sylvia Aguilera, José Merino y Mara Hernández, "La esquina entre seguridad y justicia: relato de dos iniciativas y una reforma”, en Mara Hernández et al. (eds.), Un congreso sin mayorías, México, Flacso-Centro de Colaboración Cívica, 2009.

${ }^{36}$ En 2007 Calderón presentó la mejora del medio ambiente como una de sus principales metas, pero el énfasis en esta política disminuyó pronto ante las fuertes críticas a su programa de reforestación. Su más importante logro doméstico en 
A estos cambios se sumaron otros de tipo partidario. En junio, militantes afines al presidente ganan la mayoría del Consejo Nacional del PAN y en diciembre uno de sus colaboradores más cercanos, Germán Martínez, sería electo presidente del pan, lo que terminó de definir a su favor la lucha que había entablado con Manuel Espino por el control de partido.

Como se puede observar, aunque no todo le fue favorable (al PAN no le fue bien en las elecciones de ese año en Yucatán y Veracruz, y el crecimiento económico descendió de $4.8 \%$ en el año anterior a 3.3\%), en general 2007 fue un año de triunfos para el presidente. Acaso gracias a éstos, su porcentaje de aceptación subió de alrededor de 60 a 66 y $65 \%$ en febrero y mayo de ese año. ${ }^{37}$ Otro factor que pudo haber contribuido a ello fue el cuidado que mantuvo sobre su imagen. Este fue, como dije anteriormente, un acierto de Calderón desde la campaña. Ya como presidente continuó preocupándose por evitar cualquier descuido en las formas y protocolos o en la imagen de su esposa -que en realidad ella misma se encargó de cuidar escrupulosamente a lo largo de todo el sexenio-, así como por mostrar un claro control de su gabinete. Aunque, coincidente con el bajo perfil de los secretarios ya señalado, dicho control quizás llegó inclusive a grados extremos; por ejemplo, a los secretarios les estaba vedado dar anuncios importantes y cambió a 23 de ellos durante su administración.

El año 2008 inició con uno de los primeros de estos cambios: Francisco Ramírez Acuña sale de la Secretaría de Gobernación y entra a ella Juan Camilo Mouriño (quien de hecho, según varios de los entrevistados, había estado ejerciendo las funciones de coordinación político-administrativa desde la Oficina de la Presidencia). Este año el presidente logró impulsar dos reformas. Por un lado, después de varios meses de negociaciones en las que hubo que conciliar la iniciativa presidencial con otra orientada a la protección del debido proceso, en marzo el congreso aprobó la reforma de seguridad y justicia (se publicó en el Diario Oficial en

la materia sería la Ley General de Cambio Climático, que no se aprobaría sino hasta junio de 2012.

${ }^{37}$ Consulta Mitofsky, op. cit. 
junio). Aunque en algunos de sus aspectos involucraba un proceso de implementación de varios años, la reforma le daba al Ejecutivo mayor capacidad persecutoria a la vez que iniciaba la transición de una justicia de tipo inquisitivo a una de tipo acusatorio. Ese mismo mes, se inició un operativo militar más, esta vez en Ciudad Juárez, Chihuahua.

$\mathrm{Al}$ mes siguiente, Calderón enviaría al Congreso una serie de iniciativas en materia energética, dirigidas especialmente a reformar el régimen de Pemex. Días después, López Obrador da a conocer en la prensa que, durante su estadía en la Secretaría de Energía, Mouriño había firmado contratos con PEMEx como apoderado de la empresa de su familia e inició una movilización social en contra de la reforma. Con todo, las negociaciones avanzaron y en los siguientes meses la iniciativa fue discutida en una serie de foros organizados por el Senado. Si bien la propuesta original del presidente fue modificada, la reforma fue aprobada por el congreso en octubre y publicada en noviembre en el Diario Oficial de la Federación. Aunque no constituyó una reforma radical, introdujo algunos cambios, como un nuevo régimen de contratos orientado a una provisión más eficiente de los bienes y servicios; una mayor autonomía para PEMEx; la creación de la Comisión Nacional de Hidrocarburos, entre otros, dirigidos a aumentar la eficiencia y la inversión en el sector. ${ }^{38}$

No obstante estos éxitos relativos, en el mismo 2008 también se dieron varios eventos desafortunados. En junio, es secuestrado (y poco tiempo después asesinado) el hijo de Alejandro Martí, un prominente empresario; pronto se convirtió en un caso que ponía en duda la capacidad del gobierno para combatir al crimen organizado. En un evento público con diversas autoridades responsables de la seguridad, el empresario dio un discurso que impactó a la opinión pública (abiertamente les dijo: "si no pueden, renuncien”) y al poco tiempo fundó una organización de la sociedad civil, México S.O.S., para promover la seguridad pública. Al mes

38 Gabriel Farfán y Ana Lucía García, "De la confrontación nació el acuerdo: la reforma de Petróleos Mexicanos”, en Mara Hernández et al. (eds.), Un congreso sin mayorías, México, Flacso-Centro de Colaboración Cívica, 2009. 
siguiente, 24 personas fueron ejecutadas en el Estado de México y, aún peor, dos granadas explotaron en pleno festejo de la independencia en la plaza central de Morelia, Michoacán, matando a ocho personas e hiriendo aproximadamente a otras cien.

El año terminó con más malas noticias. El 4 de noviembre se desploma cerca de la residencia presidencial el avión en el que viajaba Mouriño y mueren todos sus tripulantes. Oficialmente se argumentó que fue un accidente. Aunque quizá lo fue, el trágico suceso contribuyó al creciente clima de inseguridad, además de que el presidente perdió al colaborador en el que más confiaba. Lo sustituyó Fernando Gómez-Mont, un compañero de bancada legislativa de Calderón cuando éste fue diputado federal a principios de los años noventa pero que no tenía experiencia ejecutiva ni presencia política a nivel nacional. En 2008, las defunciones por homicidio fueron 14006, mientras que en 2007 habían sido 8 867, lo que representó un aumento de $57 \% .{ }^{39} \mathrm{~A}$ su vez, el crecimiento de la economía fue de $3 \%$, una tasa aún menor que la ya de por sí reducida de 2006, por lo que la "economía competitiva y generadora de empleo" ofrecida por el presidente empezaba a resultar un objetivo lejano.

Del análisis de los dos primeros años de gobierno, es posible decir que, en relación a las reformas pensionaria, fiscal, electoral y energética, Calderón planteó una agenda en cierta medida pertinente, con objetivos de cambio hasta cierto punto importantes a la vez que factibles de alcanzar. Sin embargo, en un contexto que como vimos era favorable para el liderazgo, podía haberse esperado una agenda más ambiciosa en cuanto a variedad de temas y

${ }^{39}$ INEGI, "Boletín de prensa número 288/13. En 2012 se registraron 26 MIL 037 homicidios", Aguascalientes, INEGi, 30 de julio de 2013. Aunque más dudosas por varias razones (entre ellas, el establecimiento de la relación de las personas con el crimen organizado), con base en datos de la presidencia, CIDAC señala en un informe que las muertes atribuidas a la delincuencia organizada se elevaron entre 2007 y 2008 de 2826 a 6 837, un fuerte aumento de 141\% (CIDAC 2011). Puede verse también el análisis ofrecido por Guillermo Trejo, "Violencia y política en el México del bicentenario", en Rolando Cordera (coord.), Presente y perspectivas, México, CIDE/FCE/COnaculta/IneHrm/Fundación Cultural de la Ciudad de México, 2010. 
profundidad de objetivos. En todo caso, es sobre todo una segunda debilidad de la agenda -la colocación de la "guerra" contra el narcotráfico en el centro de la misma- la que en definitiva llevaría a calificarla como poco pertinente. Esta meta, que claramente concentró las energías y el protagonismo presidencial, era en realidad muy difícil de alcanzar, tanto en función de la complejidad del problema como de los recursos con los que el presidente contaba para resolverlo.

En cuanto a la complejidad, desde mucho antes del gobierno de Calderón ha sido evidente que el narcotráfico subsistirá mientras persista la demanda de drogas en Estados Unidos, con el que México comparte una frontera de más de 3000 kilómetros. Aún más, el presidente cometió el error de plantear su política como una "guerra" contra el "enemigo" del narcotráfico, en la que inevitablemente el parámetro de éxito es la "derrota" de este último; sin embargo, dicha política se asemeja mucho a una "guerra de guerrillas", en la que, primero, es difícil encontrar al enemigo y, segundo, cuando finalmente se lo encuentra y "derrota" con frecuencia se rearticula o en su caso es sustituido por algún otro grupo que pasa a ocupar la plaza (por desgracia, usualmente después de enfrentamientos encarnizados). ${ }^{40}$ Por otro lado, la carencia de recursos suficientes también hacía este objetivo difícil de alcanzar. Si bien como comandante de las fuerzas armadas el presidente podía ejercer sobre ellas un mando directo, la tasa de impunidad judicial en esos momentos ya era cercana a $100 \%$, la infraestructura de inteligencia era muy reducida y había que coordinar al menos cinco dependencias (defensa, marina, procuraduría, gobernación y seguridad); además, no contaba con el suficiente apoyo de los gobernadores, presidentes municipales y, sobre todo, policías estatales y municipales, que eran a todas luces indispensables para avanzar en la reducción del narcotráfico.

40 Posteriormente, el presidente sustituyó el término "guerra" por el de "lucha”; sin embargo, probablemente era ya demasiado tarde; además, no se modificaron el lugar central de esta política en los discursos y la agenda presidenciales, la utilización predominante del ejército en ella ni la dificultad inherente para establecer en este ámbito parámetros claros que permitieran mostrar avances. 
Se ha dicho que Calderón colocó este tema en el centro de la agenda presidencial porque necesitaba ganar legitimidad. Es posible que él lo haya percibido así. Sin embargo, en realidad esa necesidad no parecía existir: las críticas a su legitimidad provenían principalmente de una parte de la izquierda, la de López Obrador, quien además ya había tenido que abandonar, bastante desgastado, la avenida Reforma. Hay además varios otros factores que hacen ver la decisión de asociar tan enfáticamente su gobierno a dicho tema como una decisión impulsiva, como los buenos niveles de aceptación popular que el presidente tenía al inicio de su periodo, ${ }^{41}$ las advertencias contra la ofensiva militar que explícitamente le hicieron Fox y otros funcionarios, la reducida posibilidad de mostrar avances significativos en esta materia, así como el amplio abanico de reformas pendientes de entre las cuales el presidente podía escoger para desarrollar una agenda. ${ }^{42}$

En cuanto al antes mencionado "palanqueo inclusivo", aunque el presidente parecía más bien concentrado en el tema del narcotráfico, para alcanzar las reformas actuó en cierta medida estratégicamente, en la medida en que promovió negociaciones con el PRI y hasta cierto punto el PRD. Gracias a ello, en estos primeros dos años obtuvo resultados, si bien fueron modestos. La reforma pensionaria abarcó diversos cambios, pero uno de los principales fue que abrió la posibilidad de que los derechohabientes migraran sus cuentas a un régimen individualizado, a fin de reducir el déficit del régimen pensionario del issste. Aunque a largo plazo este cambio puede tener efectos significativos,

${ }^{41} \mathrm{Y}$ al parecer también de legitimidad. Nicolás Loza, Legitimidad en disputa. Zedillo, Fox, Calderón, México, Flacso, 2008.

42 En un documento publicado en junio de 2011, Calderón argumentó que inició la lucha contra el crimen organizado porque existían altos niveles de violencia y rechazó que tal lucha hubiera aumentado esos niveles. Sin embargo, esto no coincide con lo que las fuentes indican (incluso las oficiales). De acuerdo al INEGI (2012), en 2006 el número de homicidios fue de 10452 y de acuerdo al CIDAC (2011), el número de asesinatos asociados al crimen organizado fue de 2826 . De acuerdo a las mismas fuentes, a partir de ese año los homicidios habían aumentado en forma constante (con la excepción de 2007) hasta llegar a 27213 en 2011, mientras que los asesinatos relacionados con el crimen organizado habían tenido un aumento ininterrumpido hasta llegar a 15273 en 2010. 
el porcentaje de derechohabientes que migró al nuevo régimen fue muy reducido (de aproximadamente $20 \%$ ), ${ }^{43}$ por lo que los resultados en esta materia fueron menores (además de polémi$\cos$ ). La reforma fiscal por su parte aumentó sólo en un porcentaje menor el ingreso tributario en relación al PIB (entre uno y dos puntos),${ }^{44}$ lo cual sólo mitigó su insuficiencia. La reforma energética implicó cambios en el régimen de pemex, en su momento presentados como "históricos", pero que en realidad resultaron insustanciales para aumentar significativamente la inversión y la capacidad en materia petrolera. ${ }^{45}$ La reforma electoral trató de mejorar la deteriorada imagen del IFE cambiando a su presidente $y$, en forma escalonada, a los consejeros electorales, entre otros cambios. Aunque esta reforma se quedó algo corta en relación a la magnitud de la crisis de 2006 (no alteró por ejemplo el cuoteo partidista del consejo que se había comenzado a aplicar desde unos años antes, ni estableció controles más efectivos a los gastos de campaña), el Instituto superó la prueba de la elección intermedia del año 2009 y la aún más importante del año 2012, lo cual fue importante. En todo caso, aun si involucraban cambios modestos, en los primeros años estas reformas le permitieron al presidente mostrar cierta capacidad política para impulsar el avance del país.

No se puede decir lo mismo, sin embargo, en materia de narcotráfico. Además de la poca factibilidad del objetivo en sí mismo, muy pronto todo empezaría a indicar que la estrategia adoptada no era la adecuada. En primer lugar, si el problema era la infiltración del narcotráfico en las altas esferas de la política, como se decía era el caso en Michoacán, el primer estado al que mandó al ejército, instrumentos como el blindaje de las campañas electorales, la lucha contra la corrupción estatal o la profesionalización

${ }^{43}$ Entrevista a funcionario público del issste, México, D. F., 27 de noviembre de 2010 .

${ }^{44}$ Roberto Castellanos, Claudia Suárez y Vania Montalvo, "La reforma fiscal 2008”, en Mara Hernández et al. (eds.), Un Congreso sin mayorias: mejores prácticas en negociación y construcción de acuerdos, México, Flacso, 2009.

${ }^{45}$ Entrevista a funcionaria pública de Pemex, México, D. F., 10 de abril de 2014. Véase también Carlos Elizondo, Por eso estamos como estamos, México, Random House Mandadori, 2011, p. 177. 
hubieran sido respuestas más eficaces a ese asunto que la intervención militar. Por otro lado, definido el problema como el de la existencia misma del crimen organizado, algunos autores ${ }^{46}$ han señalado que en lugar de haber lanzado una ofensiva punitiva, generalizada y en buena medida dirigida contra las cabezas de los carteles, se debió haber instrumentado una estrategia "disuasiva" -esto es, focalizada en ciertas áreas específicas, por ejemplo donde actuaban los carteles más violentos, a fin de reducir la violencia-, así como más integral -con programas para prevenir el delito, restituir el tejido social y disminuir la pobreza (en otras palabras, en los términos utilizados en la primera sección, con una mezcla o combinación de recursos estatales en lugar del uso predominante de uno de ellos).

Así, para finales de 2008 era ya claro que la lucha contra el narcotráfico implicaba mayores dificultades que las originalmente previstas; aún más, la estrategia militar no sólo no estaba aminorando el problema, sino que estaba ya catalizando el aumento de los homicidios $^{47}$ (que por cierto venían disminuyendo desde 1990) y de otros delitos asociados al crimen organizado, como la extorsión y el secuestro; ${ }^{48}$ el clima de inseguridad en general había también aumentado considerablemente por los enfrentamientos entre el ejército y los grupos criminales o entre estos mismos, así como por las violaciones a los derechos humanos. Todos estos efectos estaban ensombreciendo los logros obtenidos en los otros ámbitos y, por su ritmo y notoriedad, era claro que pronto erosionarían -si no lo estaban haciendo ya- el capital político del presidente.

${ }^{46}$ Entre otros, Guerrero, "La raíz de la violencia”, Nexos, junio de 2011.

47 Alejandro Hope, "Violencia 2007-2011. La tormenta perfecta", Nexos, noviembre de 2013.

${ }^{48}$ La tasa de extorsión por cada 100000 habitantes era en 2007 de 2.84 y en el 2008 aumentó sustancialmente a 4.37; en 2009 y 2010 esta cifra llegó a 5.61 y 5.34, respectivamente. En 2007 la tasa de secuestros por cada 100000 habitantes era de 0.40 y para 2008 se duplicó a 0.81 secuestros. En 2009 fue de 1.03 y en 2010, 2011 y 2012 de 1.07. 1.23 y 1.21, respectivamente. Secretariado Ejecutivo del Sistema Nacional de Seguridad Pública, "Tasa por cada 100 mil habitantes", Incidencia delictiva, 16 de abril de 2014, http:/ / www.secretariadoejecutivosnsp.gob.mx/es/ SecretariadoEjecutivo/090820132 
De esta manera, aunque como se dijo antes los efectos negativos de una ofensiva militar contra el narcotráfico eran previsibles desde 2006, para fines de 2008 eran ya evidentes, por lo que parecía ser el momento de hacer ajustes. ${ }^{49}$ Este no fue sin embargo el caso: en 2009 la lucha contra el narcotráfico, además de mantener su intensidad, alcanzó al ámbito electoral. En cuanto a lo primero, continuaron los operativos -como por ejemplo la detención en mayo de varias decenas de funcionarios estatales y municipales en Michoacán por presuntos nexos con el crimen organizado. ${ }^{50}$ Ese mismo mes -dos años y medio después de iniciada la guerra contra el narcotráfico-, el presidente presentó su Programa para la Seguridad Nacional 2009-2012. En 2009 hubo de nuevo un aumento de los homicidios, que fueron $19803,{ }^{51} 41 \%$ más que el año anterior. ${ }^{52}$ En cuanto a lo segundo, con vistas a las elecciones legislativas de julio, en marzo el dirigente del PAN empezó una fuerte campaña de declaraciones públicas contra el PRI, que se basó en vincularlo con el crimen organizado (obviamente con la aprobación del jefe del Ejecutivo). ${ }^{53}$ Así, el presidente pasaría de la estrategia negociadora inicial, "a nivel de cancha", a una

${ }^{49}$ La estrategia seguida por Calderón de atacar frontalmente al narcotráfico parece haber sido un importante factor del incremento sustancial en el número de homicidios en estos años, entre otras cosas porque ocasionó mayores conflictos entre grupos criminales rivales. Sin embargo, no fue el único; por ejemplo, desde 2004 Estados Unidos había retirado la prohibición para vender armas de alto calibre (Hope, art. cit.). Con todo, la presencia de varios de estos factores y su peligrosa combinación eran conocidas desde finales de la administración de Fox, y justificaba las advertencias sobre los efectos negativos de una ofensiva militar que se le hicieron a Calderón, pero que éste desoyó.

${ }^{50}$ En realidad, sin suficientes pruebas, por lo que dos años después todos ellos serían liberados.

51 INEGI, "Boletín de prensa número 288/13...".

${ }^{52}$ Las muertes relacionadas con el crimen organizado pasan de 6837 a 9614 , un aumento también de $41 \%$ (CIDAC, 2011).

53 También producto de las elecciones intermedias, Josefina Vázquez Mota renuncia a la Secretaría de Educación Pública para irse de candidata a diputada federal y es sustituida por Alonso Lujambio. Este tuvo que continuar respetando la co-formulación de la política educativa que el presidente había pactado con la líder del SNTE desde el principio de la administración y con la que cerró toda posibilidad de reformas en el sector. 
estrategia más bien de tipo plebiscitario (la cual por cierto le había criticado a Fox).

En la primera mitad de 2009 un suceso le ofrecería al presidente otra oportunidad para ejercer un papel protagónico. Desde los primeros días de abril, la Secretaría de Salud había detectado un incremento en el número de casos de influenza en el país, atípico tanto por estar ocurriendo en este mes -en lugar de diciembre y enero- como por estar atacando a adultos jóvenes -no a adultos mayores y niños- y que había ya causado algunas defunciones. Ante estos hechos, el 17 de abril la secretaría decretó una alerta epidemiológica nacional e inició los trámites para enviar muestras a laboratorios de Estados Unidos y Canadá. El jueves 23 de abril se informó que en 17 de las muestras analizadas aparecía un nuevo virus (AH1N1), por lo que después de lo que al parecer fue una tensa reunión en Los $\operatorname{Pinos}^{54}$ el gobierno suspendió las clases primero en el Distrito Federal y el Estado de México y más tarde en el resto del país. El miércoles 29, el presidente apareció en cadena nacional y anunció que el gobierno suspendería actividades no prioritarias entre el 1 y el 5 de mayo. Las clases en el nivel de educación básica sólo se restablecieron hasta el día 11.

En estos días el presidente se presentó como un gobernante decidido y firme que defendía "a la patria" (como decía frecuentemente en sus discursos), en esta ocasión -se argumentó- evitando una epidemia que hubiera causado muchos fallecimientos en México y posiblemente en otras naciones. Aunque la necesidad de tomar las decisiones arriba descritas ha sido materia de discusión, ${ }^{55}$

${ }^{54}$ La decisión se tomó en un contexto de alta incertidumbre. A favor de la emergencia sanitaria estaba la posibilidad de que en unos pocos días el virus se extendiera y matara a miles de personas. En su contra, sin embargo, había varios tipos de razones. En términos sanitarios, por ser un virus nuevo no se conocía en realidad su grado de letalidad; además, los reportes de casos recibidos por la Secretaría de Salud eran de casos sospechosos de AH1N1, no de casos confirmados, ya que en México no se tenía la capacidad para confirmar de manera inmediata qué tipo de virus tenían los pacientes. En términos económicos, era previsible que las medidas drásticas afectarían a la economía -especialmente la actividad turística-, que de por sí ya mostraba un marcado decrecimiento.

${ }^{55}$ Bradly J. Condon y Tapen Sinha, "The Effectiveness of Pandemic Preparations: Legal Lessons from the 2009 Influenza Epidemic”, International Federation 
lo que sí fue un hecho fue que tuvieron graves consecuencias para la economía y la imagen externa del país. Para la sociedad fueron días de preocupación e incertidumbre, en los que se evidenciaron las fuertes carencias de los servicios públicos de salud. Aparte de las dudas sobre la necesidad de haber decretado la emergencia sanitaria, otros la percibieron como un ejemplo más del impulso protagónico del Ejecutivo, ${ }^{56}$ que imponía decisiones altamente costosas para la nación y que cada vez alienaban más a la clase política.

El 5 de junio se daría otro evento trágico, esta vez menos sujeto al control del presidente: el incendio de la guardería ABC, del Instituto Mexicano del Seguro Social, en Hermosillo, Sonora. Más de veinte niños resultaron gravemente heridos y murieron otros 49. Aparte del impacto que la tragedia causó en la opinión pública nacional, las movilizaciones, investigaciones y juicios que motivó en contra de los dueños de la estancia infantil, así como de diversos funcionarios federales y locales, serían motivo constante de titulares de primera plana en los siguientes años.

A un mes de la elección intermedia -y por el resto del sexenio-, este evento afectó la imagen del gobierno de Calderón porque mostró la ineficiencia, tráfico de influencias y nepotismo con que se había estado gestionando esa guardería (y entonces potencialmente todas las demás): por un lado, su ubicación en un local inadecuado facilitó la generación del incendio; por el otro, muchos de sus dueños tenían puestos en el gobierno o en el PRI del estado, o eran parientes de funcionarios estatales o federales. Si bien esto ameritaba una reacción enérgica por parte del gobierno, la administración se enredó en pretextos legales y respondió tibiamente. La imagen gubernamental se vio también afectada por la fuerte crisis económica por la que ya estaba pasando el país (la economía había decrecido $1.1 \%$ en el último cuarto del 2008, así como 5.3 y $6.9 \%$ en el primer y segundo trimestres de 2009). ${ }^{57}$

of Red Cross and Red Crescent Societies, 2009, en http://www.ifrc.org/Global/ Publications/IDRL/working-papers/pandemic-preparedness-sept-2009.pdf

56 Núñez, op. cit.

${ }^{57}$ Véase INEGi, Banco de información económica/ cobertura temática/indicadores económicos de coyuntura/producto interno bruto trimestral, base 2008, 
El 5 de julio llegó finalmente la prueba que muchos estaban esperando: las elecciones legislativas intermedias. En ellas, el presidente sufrió un duro golpe político: el PAN vio reducido de 206 a 147 su número de diputados (lo cual se sumaba a las ya referidas derrotas de 2007 en las elecciones en Yucatán y Veracruz). En contraste, el PRI había más que duplicado sus curules: obtenía 242, lo que claramente le transfería la posibilidad de ejercer el liderazgo legislativo, especialmente cuando uno de sus aliados de los últimos años, el Partido Verde Ecologista de México (PVEM), había obtenido 22 diputaciones, con las que podía formar una mayoría. Ante semejante caída, ${ }^{58}$ renunció Germán Martínez, el líder del PAN que había encabezado la ofensiva contra el PRI; fue sustituido por César Nava, lo que a su vez abrió el paso a Luis Felipe Bravo Mena en la Secretaría Particular.

Fiel a su tendencia a defenderse atacando, Calderón respondió a la derrota de julio anunciando dos meses después un "decálogo" de objetivos que deberían conseguirse en la segunda mitad de su mandato: 1) reducción de la pobreza, 2) cobertura universal en salud, 3) educación de calidad, 4) reforma de las finanzas públicas, 5) modernización de las empresas estatales de energía, 6) reforma de las telecomunicaciones, 7) reforma laboral, 8) desregulación, 9) ampliación de la lucha contra la delincuencia organizada (no obstante los resultados descritos) y 10) reforma política. En los últimos meses del año, el presidente desarrolló acciones

http:/ /www.inegi.org.mx, consultado el 15 de octubre de 2014. PIB en serie original corregida por efectos de calendario a precios de 2008 .

${ }^{58}$ Es cierto que en general las elecciones intermedias constituyen un difícil reto para los presidentes y sus partidos. En este sentido, sin embargo, haría al menos dos acotaciones. Por un lado, el resultado de dichas elecciones puede variar y no es lo mismo mantener un número similar de legisladores o perder sólo algunos que perder varias decenas. Por otro lado, que el partido en el gobierno pierda curules en estas elecciones no representa una "ley de hierro": hay casos en los que el liderazgo político del presidente ha conducido incluso a un aumento significativo en el número de asientos de su partido, como en las elecciones intermedias del sexenio de Carlos Salinas, cuando el PRI ganó 58 diputaciones adicionales. Finalmente, si bien la crisis económica no era algo que el presidente podía controlar y sin duda afectó en alguna medida la imagen gubernamental, para julio de 2009 sus efectos aún no se manifestaban completamente sobre la población. 
importantes sobre todo en tres de estos puntos, aunque en realidad sólo representarían paliativos ante los problemas y ayudaron poco a evitar o incluso coadyuvaron a la caída en la capacidad e imagen presidenciales.

En relación al primer punto, en septiembre propuso un gravamen de $2 \%$ al consumo para ser aplicado a programas contra la pobreza. Este, sin embargo, fue rechazado en el congreso. Con todo, en octubre logró la aprobación del aumento del IVA, ISR e IDE, lo que aminoró parcialmente los profundos efectos financieros, económicos, sociales y políticos de lo que sería la profunda crisis económica de ese año (en el cual la economía decreció nada menos que un $6 \%$, una caída que no se veía desde la crisis de 1994).

En relación al quinto punto, el 10 de octubre -en otra más de las acciones de fuerza que tanto gustaban al presidente- policías federales tomaron las instalaciones de la Compañía de Luz y Fuerza del Centro, que sería liquidada como tal para ser absorbida por la Compañía Federal de Electricidad. Con ello, el presidente "mataba dos pájaros de un tiro": cerraba una compañía altamente ineficiente y desaparecía un sindicato simpatizante de la izquierda. Si bien con esta acción buscaba aparecer como un modernizador y opositor de los "poderes fácticos", para esas alturas la sombra de su continuado e incondicional apoyo a su aliada Elba Esther Gordillo, dirigente de un sindicato que impedía cualquier mejora en la educación, evidenciaba su parcialidad.

Finalmente, en diciembre, el presidente envió un paquete de diez propuestas de reforma política al congreso (de las cuales las más importantes eran la segunda vuelta para la elección presidencial y la reelección consecutiva de alcaldes y ayuntamientos, así como de los legisladores federales); sin embargo, el PRI -atacado unos meses antes por el presidente y con la vista ya puesta a las próximas elecciones presidenciales- rechazó aprobarlas el siguiente año (poco más tarde, en 2011, tres de ellas serían aprobadas, sin incluir la reelección, pero sujetas a entrar en vigor hasta 2015). Aunque en los primeros meses de 2009 habían aumentado a 66 y $65 \%$, los índices de popularidad del 
presidente en el tercer y último cuarto bajaron a 62 y $58 \%$, respectivamente. ${ }^{59}$

De esta manera, si Calderón, concentrado en atacar al crimen organizado, se había visto poco dispuesto a impulsar verdaderamente una agenda de "reconstrucción" al principio de su sexenio, cuando tenía un contexto relativamente favorable, lanzaba ahora un decálogo de reformas cuando su margen de maniobra en el congreso se había visto severamente reducido. Así, su impulsividad y protagonismo lo llevaban a cometer de nuevo un error estratégico, ya que al no reconocer el escenario adverso, que más que una agenda presidencial exigía una agenda negociada dentro del congreso, las propuestas unilaterales del Ejecutivo sólo conducirían a la acumulación de "derrotas anunciadas", que a su vez acentuaron el problema que se quería resolver: el declive de su capacidad política. Como dije en la primera sección, más que ser todo el tiempo proactivo, un presidente debe evaluar constantemente los tiempos y los ámbitos tanto para la acción como para la abstención, la resistencia y la corrección, lo cual evidentemente no fue el caso con el presidente Calderón. ${ }^{60}$ Como se verá en el siguiente apartado, en la segunda mitad del sexenio el declive en la capacidad política presidencial continuaría, junto con el de los porcentajes de aprobación. En contraste, justo ese mismo periodo

${ }^{59}$ Consulta Mitofsky, op. cit.

60 Jo Tuckman (Mexico: Democracy Interrupted, New Haven, Yale University Press, 2012, p. 72) relata un suceso que mostraba cómo la necesidad protagónica del presidente lo llevaba a tomar decisiones estratégicamente equivocadas: cuando un reportero de Radio Fórmula le preguntó por qué había lanzado esas iniciativas en un contexto tan adverso, Calderón respondió: "no quiero ser recordado como un presidente más”. En general, ningún presidente lo quiere ser; el problema emerge cuando la necesidad de pasar a la historia le impide ver la realidad y adaptarse a ella. Un contraste interesante en este sentido lo ofreció Bill Clinton, cuando, ante la derrota del partido demócrata en el congreso, viró hacia la agenda del partido republicano con el fin de obtener logros importantes (por ejemplo, la reducción del déficit estatal). Eisenhower por su parte más bien limitó su agenda para evitar sufrir fuertes derrotas y empeorar su posición. Como dije en la primera sección, más que necesariamente proactivo, un presidente debe estar evaluando los tiempos y los ámbitos tanto para la acción como para la abstención, la resistencia y la corrección. 
será en el que comenzará el ascenso mediático de Enrique Peña Nieto, gobernador priista del Estado de México.

2010-2012: DEL AGRAVAMIENTO DE LA INSEGURIDAD

A LA PÉRDIDA DE LA PRESIDENCIA POR EL PAN

Si bien 2010 era el año del Bicentenario de la Independencia y el Centenario de la Revolución, en el que llamaría constantemente a la unidad del país, el presidente no logró que el congreso aprobara la reforma política ni otra reforma más que iba a proponer en marzo, la reforma laboral. Peor aún, ese año se observó la fractura de su equipo. Ante las elecciones para gobernador que tendrían lugar en los meses siguientes en varios estados, en febrero el dirigente del PAN logra establecer una alianza con el PRD, contra la opinión del secretario de Gobernación. En consecuencia, GómezMont primero toma la sorprendente decisión de renunciar a ese partido y, más tarde -cuando en julio las coaliciones del PAN y el PRD ganan las elecciones en Oaxaca, Puebla y Sinaloa- sale de ese puesto (junto con Gerardo Ruiz Mateos, secretario de Economía, quien es regresado a la Oficina de la Presidencia). Lo sustituyó Francisco Blake, un funcionario local también prácticamente desconocido a nivel nacional (era el Secretario General de Gobierno del estado de Baja California). La decisión de aliarse con el PRD ahondará además la fractura con el PRI, cuya dirigente Beatriz Paredes denunció que Nava estaba rompiendo un acuerdo en el que se había comprometido a no aliarse con la izquierda. Poco después, en noviembre, se dio en el PAN una divisiva lucha por la dirigencia nacional entre el grupo que apoyaba al candidato calderonista, Roberto Gil, y otro que promovía la candidatura de Gustavo Madero, el cual resultó ganador. De esta manera, si el año anterior había perdido casi un tercio de diputaciones panistas y con ello la posibilidad de ejercer cierto liderazgo legislativo, este año el presidente perdería incluso el control de su propio partido.

En el ámbito de la seguridad los resultados no fueron mejores. El año en el que se festejaban doscientos años de la Independencia y cien de la Revolución fue todavía más violento que el anterior: 
hubo 25757 homicidios, $30 \%$ más que la ya elevada cifra de 2009 (19803). ${ }^{61}$ Algunas de esas muertes alcanzaron las primeras planas de los periódicos nacionales. Por ejemplo, en enero un comando armado atacó a sesenta jóvenes en Ciudad Juárez y hubo 14 heridos y 14 muertos. Al mes siguiente mueren otros 13 muchachos en esa misma ciudad, a los que se acusa de ser parte del crimen organizado. En una declaración que será fuertemente criticada, ese mes Calderón declaró que $90 \%$ de las víctimas en el conflicto con los cárteles estaba vinculado con el crimen organizado. En marzo mueren dos estudiantes en las afueras del Tecnológico de Monterrey en medio de un enfrentamiento en esta ciudad en el que participó el ejército, a los que también inicialmente se acusa de ser parte del crimen organizado. En mayo secuestran a Diego Fernández de Cevallos y fue liberado hasta noviembre. Calderón se tuvo que abstener de investigar y castigar su secuestro, a pesar de toda la retórica alrededor del "ataque frontal" contra la delincuencia, a solicitud de la familia del político panista. El 13 de junio Calderón publica un documento ("La lucha por la seguridad") en los diarios nacionales; en él confrontó algunas de las críticas que se venían haciendo a su política, ${ }^{62}$ pero reiteró que "sin dejar de reconocer lo delicado de la situación y lo mucho que falta por hacer, la estrategia avanza en la dirección necesaria y establecida desde el principio". Ese mes asesinaron a Rodolfo Torres Cantú, candidato a gobernador de Tamaulipas. En este mismo estado estalla en julio un coche bomba y en agosto, mes en que el gobierno federal inició unos "diálogos por la seguridad" con diversos activistas y académicos, se encuentran 72 cadáveres de migrantes centroamericanos

${ }^{61}$ De acuerdo al CIDAC (2011), 15273 de ellos asociados al crimen organizado, un aumento de casi $60 \%$ respecto a 2009 .

62 Desde la segunda mitad de 2009, la Comisión Nacional de los Derechos Humanos, Human Rights Watch, así como diversos legisladores y analistas venían insistiendo en la necesidad de revisar la estrategia seguida contra el narcotráfico. Aparte del documento de junio, en enero de 2010 uno de los asesores de seguridad del presidente, Joaquín Villalobos, había publicado en la revista Nexos un artículo en que defendía la estrategia adoptada. Su título, "Doce mitos de la guerra contra el narco", era indicativo de la actitud y la percepción en los Pinos hacia las críticas a dicha estrategia. 
asesinados por un grupo criminal. En octubre, Calderón envió al Congreso una propuesta para crear el mando único policial. Esta iniciativa entró a la "congeladora" legislativa, aunque sí se aprobó una ley contra el secuestro (el cual, además de haber afectado a un prominente político panista, para esa fecha ya se había más que duplicado).

El 15 de septiembre se festejó finalmente el bicentenario de la Independencia. Aunque el desfile en el Zócalo de la ciudad de México fue espectacular y las ceremonias del grito transcurrieron sin sobresaltos en las capitales estatales, los festejos estuvieron marcados por la preocupación sobre posibles actos terroristas (como los ocurridos unos meses antes en Tamaulipas y el 15 de septiembre de 2008 en Morelia), las múltiples fallas en la organización de las celebraciones (por la que pasaron siete coordinadores generales) y el escándalo por el dispendio en la construcción de su obra más emblemática, la "Estela de Luz" en la avenida Reforma de la ciudad de México. Esa noche el presidente apareció sonriente ante el magno evento en el zócalo capitalino, pese a que en realidad su nivel de aprobación había venido cayendo constantemente y para el final de 2010 era ya ocho puntos menor (pasó de un promedio anual de $62.3 \%$ el año anterior a uno de $54.2 \%) .{ }^{63}$

Calderón inició el siguiente año relevando a Bravo Mena en la Secretaría Particular (se iba a competir por la gubernatura del Estado de México) y a Juan Molinar en la Secretaría de Comunicaciones y Transportes (quien había apoyado a Madero unos meses antes). Roberto Gil y Dionisio Pérez Jácome, respectivamente, pasarían a ocupar sus carteras. En abril finalmente se da la aprobación en el congreso de tres de las reformas políticas que Calderón había propuesto en 2009 (aunque su aprobación en las legislaturas estatales se alargaría durante todo 2011 y buena parte de 2012). En mayo, se firma el acuerdo para la reforma de la carrera magisterial, que involucraba un nuevo sistema de evaluación del desempeño y la realización de concursos para la ocupación de plazas (que sin embargo tendrían poco impacto real) ${ }^{64}$ Sin embargo, como se verá

${ }^{63}$ Consulta Mitofsky, op. cit.

64 Abraham Sánchez, "Análisis de las reformas educativas de la educación 
más abajo, prácticamente hasta los últimos meses de este año-cuando giró hacia eventos de tipo electoral-, la atención del país estuvo centrada en los acontecimientos relacionados con la seguridad.

En febrero de 2011, Florence Cassez, ciudadana francesa acusada de secuestro, fue condenada a sesenta años de cárcel. El proceso en su contra venía siendo motivo de fuertes cuestionamientos a nivel nacional e internacional. Unos años antes, Genaro García Luna, quien ahora era nada menos que el secretario de Seguridad Pública, había organizado un montaje televisivo con la acusada que afectó irremediablemente su debido proceso legal. No obstante la escalada de críticas, Calderón se aferró a defender la condena y a mantener a su secretario. Francia anunció que el "Año de México" que estaba por celebrarse en aquél país giraría alrededor de su ciudadana, ante lo cual al gobierno mexicano no le quedó más remedio que cancelar su participación. Cassez fue liberada en 2013.

También en el mes de febrero dos agentes de Estados Unidos fueron atacados, y muere uno de ellos. En marzo fue asesinado el hijo de Javier Sicilia, por lo que éste lideró en los siguientes meses un movimiento nacional en contra de la violencia y la política de seguridad ("Movimiento por la Paz"), en medio de continuos asesinatos masivos en diversos estados del país. En uno de ellos, ocurrido en agosto, un grupo criminal incendió en pleno día un casino en la ciudad de Monterrey, por el cual murieron 52 personas. Presionado, en la segunda mitad del año por fin el presidente comenzó a hacer cambios en los operativos con el fin de reducir sus efectos sobre el número de homicidios, lo que junto con otros factores, como la mayor fortaleza del aparato de seguridad o el debilitamiento de los carteles más violentos, probablemente incidió para que el siguiente año bajara la tasa de aumento de homicidios. ${ }^{65}$

En noviembre la hermana de Calderón pierde la gubernatura de Michoacán contra el candidato del PRI (sumándose a la derrota que Bravo Mena había sufrido en el Estado de México en julio).

básica del periodo 200-2012”, en Miguel Ángel Vértiz (coord.), Estudios sobre reformas educativas, México, Universidad Pedagógica Nacional, 2013.

${ }^{65}$ Eduardo Guerrero, "La estrategia fallida", Nexos, diciembre de 2012; Tuckman, op. cit., p. 175 . 
Enrique Peña Nieto y Andrés Manuel López Obrador son designados candidatos presidenciales del PRI y el PRD, respectivamente. En contraste, en el PAN Ernesto Cordero -el candidato del presidente-, Santiago Creel y Josefina Vázquez Mota se enfrascaron en una competencia que acabó debilitando a los tres. Este mismo mes otra tragedia enlutó al gobierno de Calderón, cuando se desploma el helicóptero en el que viajaba Blake. Alejandro Poiré, otro joven militante panista que hacía poco había llegado a la dirección del CISEN, se convierte en el quinto secretario de Gobernación.

En 2011 hubo 27213 homicidios, lo que representó un aumento de $5.7 \%$ respecto al año anterior. Probablemente por los factores antes referidos, entre ellos los cambios en la estrategia gubernamental, el ritmo de aumento disminuyó significativamente; sin embargo, en términos absolutos, esta cifra colocó a México ya en el nivel de un país considerado altamente violento como Brasil, con algunos estados al nivel de Honduras. ${ }^{66}$ Este año el promedio anual de aprobación del presidente cayó otros tres puntos, pasando de 54.2 a $51 \% .{ }^{67}$

Como podía esperarse ante la caída constante de su capacidad política a partir de la segunda mitad de 2009, en su último año el presidente Calderón y su partido sufrieron derrota tras derrota. En febrero, Ernesto Cordero, su favorito para la candidatura presidencial del PAN, pierde frente a Josefina Vásquez Mota. ${ }^{68}$ En forma significativa, ésta escoge como lema de campaña una palabra: "diferente”. En mayo, a dos meses de la elección presidencial, ya sólo $45 \%$ de la población aprobaba su gestión (una caída de 21 puntos desde febrero de 2009, cuando se ubicaba en 66\%).

En julio Enrique Peña Nieto ganó con suficiente holgura las elecciones presidenciales; Vázquez Mota quedó en un lejano tercer

${ }^{66}$ A septiembre de este año, la cifra de homicidios asociados al crimen organizado era de 12903 (Rafael Ch y Marien Rivera, "Números rojos del Sistema Penal”, CIDAC, octubre de 2011, http:/ / www.cidac.org/esp/uploads/1/CIFRAS.pdf). Así, de 2007 a septiembre de 2011 habría habido un total de 49674 homicidios vinculados a la delincuencia organizada.

${ }^{67}$ Consulta Mitofsky, op. cit.

68 A su vez, Cordero perdió ante Gustavo Madero la competencia por la dirigencia del PAN en mayo de 2014. 
lugar. El PAN pierde las gubernaturas que tenía en Jalisco y Morelos y es derrotado en decenas de alcaldías. Si en 2009 había perdido 64 diputaciones, ahora tuvo que restar otras 28, para quedarse con apenas 114; en el Senado pasó de 52 a 38 representantes; en contraste, el PRI obtiene 207 diputados y 52 senadores. ${ }^{69}$

En agosto, el grupo del presidente queda de nuevo en minoría en el Consejo Nacional del PAN. Calderón llamará a realizar una Asamblea Nacional Extraordinaria antes de que concluya su gobierno, pero Madero lo impide. Aunque inició sesiones el primero de septiembre, el congreso no aprobó la reforma laboral hasta noviembre, cuando ya era Peña Nieto junto con la bancada de su partido quienes construían y se adjudicaban el mérito de los acuerdos legislativos. Finalmente, tras un breve y distante saludo entre ambos, el 1 de diciembre Calderón entrega la banda presidencial para que la reciba Enrique Peña, el candidato del partido que había sido el foco de su trabajo opositor durante buena parte de su vida.

\section{LIDERAZGO PRESIDENCIAL Y ESTILO DEGISORIO CON Felipe CALDERón}

Después de un repaso general de los seis años de la administración de Felipe Calderón, ¿qué podemos concluir sobre la medida en que ejerció un liderazgo político? En otras palabras, ¿obtuvo Felipe Calderón logros importantes a través de una agenda pertinente y un palanqueo inclusivo?

Como se vio, en los primeros dos años de su gobierno el presidente actuó en cierta medida estratégicamente en relación a varias reformas -la pensionaria, la fiscal, la electoral y la energéticaobteniendo en estos ámbitos ciertos resultados, aunque más bien modestos. En 2009 planteó más reformas, que sin embargo se

${ }^{69}$ IFE, "Las elecciones del primero de julio: cifras, datos, resultados", Instituto Federal Electoral, http:/ /www.ife.org.mx/docs/IFE-v2/CNCS/CNCS-IFE-Respon de/2012/Julio/Le010712/Le010712.pdf; IFE, "LX Legislatura (2006-2012)", Integración de la Cámara de Senadores de la República Estadística de las Elecciones Federales de 2006, Instituto Federal Electoral, http://www.ife.org.mx/documentos/Estadisticas2006/senadoresrp/cam_senadores.html 
aprobarían de forma muy parcial o tardía. Así, el avance en la mayoría de las políticas públicas en su sexenio fue reducido. En las políticas sociales se avanzó en forma importante hacia la cobertura universal en salud; $;^{70}$ sin embargo, las fuertes deficiencias y carencias financieras de la misma continuaron y la situación del sistema público de pensiones sólo se mitigó. Las reformas educativas fueron superficiales y se fracasó en la obtención de una educación de calidad, ${ }^{71}$ así como en la reducción de la pobreza: los porcentajes de personas en pobreza alimentaria, de capacidades y de patrimonio, que venían bajando constantemente desde 1996, aumentaron entre 2006 y $2012 .{ }^{72}$ En el ámbito económico, no hubo realmente una reforma de las finanzas públicas. Se incorporó Luz y Fuerza del Centro a la Comisión Federal de Electricidad, pero sus deficiencias se mantuvieron. El fuertemente cuestionado régimen en materia de telecomunicaciones no se reformó; la política pública en esta área estuvo marcada por el permanente conflicto. ${ }^{73} \mathrm{La}$ reforma laboral se aprobó, pero hasta noviembre de 2012, por lo que, como dije, el crédito se lo llevaron más bien la bancada del PRI y su entonces candidato electo. No hubo una clara desregulación. En 2010, 2011 y 2012 se recuperó la economía, que por supuesto depende sólo parcialmente de las políticas gubernamentales, pero el crecimiento anual promedio del PIB en el sexenio fue de sólo 2.6\%. En materia política se aprobaron tres de las diez iniciativas de la reforma política (y no las más importantes). En cuanto a la modernización gubernamental, los avances también fueron muy modestos; si acaso hubo alguno, fue la

${ }^{70}$ Víctor Muñoz, "Las políticas del sector salud en el sexenio de Felipe Calderón”, en María Eugenia Valdés (coord.), Los problemas nacionales durante el gobierno de Felipe Calderón, México, Miguel Ángel Porrúa, 2012.

${ }^{71}$ Luis Reyes, "La alianza del SNTE con el gobierno de Calderón”, en María Eugenia Valdés (ed.), Los problemas nacionales durante el gobierno de Felipe Calderón, México, Miguel Ángel Porrúa, 2012, pp. 79-81. También Sánchez, art. cit.

72 Coneval, medición de la pobreza/evolución de las dimensiones de la pobreza, en http://www. coneval.org.mx, consultado el 18 de octubre de 2014.

${ }^{73}$ María Eugenia Valdés, "El gobierno de Felipe Calderón en el sector de la radiodifusion y las telecomunicaciones", en María Eugenia Valdés (coord.), Los problemas nacionales durante el gobierno de Felipe Calderón, México, Miguel Ángel Porrúa, 2012. 
Ley Federal de Protección de Datos Personales, mientras que hubo estancamiento o franco retroceso en otros aspectos (como el servicio profesional de carrera).$^{74}$

Como indiqué, la reforma de seguridad y justicia y en general la lucha contra el narcotráfico ocupó el lugar central en la agenda del gobierno, por lo que merece mención aparte. Los cambios legales de 2008 le dieron al Estado una mayor capacidad persecutoria y establecieron las bases para la transición hacia un nuevo sistema de justicia. Estos cambios se verían complementados con otras leyes en los siguientes años, como la ley contra el secuestro. Aparte de este más sólido andamiaje legal-institucional para combatir el crimen organizado, se duplicó el gasto en justicia y seguridad; también se quintuplicó el número de efectivos de la policía federal y se promovió la sustitución de miles de policías estatales y municipales, lo que ha hecho que ahora el ejército y la marina ya no sean el único instrumento del Estado para enfrentar al crimen. Aunque estos representan logros significativos, involucraron cambios en los medios que no pudieron asociarse a la consecución del fin para el que fueron realizados, esto es, la reducción de la criminalidad organizada. Ello se debió en buena parte a la dificultad para medir los avances en la misma; de hecho, la captura o muerte de decenas de capos por parte del gobierno, con las que a lo largo de la administración quería mostrar que la estaba reduciendo, confirmaba la impresión de que más bien estaba aumentando. Aún peor, si por un lado el avance en la reducción del narcotráfico no fue claro, sí lo fueron los efectos catalizadores de la estrategia del gobierno en el aumento de otros crímenes, como el homicidio, la extorsión y el secuestro. ${ }^{75}$ Aunque más tarde el número de homicidios comenzó a reducirse, para 2013 parecía haberse estabilizado en alrededor del doble del que se tenía en 2007, mientras que la tasa de secuestro ha continuado aumentando. ${ }^{76}$ En síntesis, en lugar de mitigarse, el problema aumentó.

${ }^{74}$ Miguel Ángel Valverde y Mary E. Hilderbrand (eds.), Transformación, lo mismo de siempre o progreso lento y con tropiezos; reformas recientes al sector público en México, México, Miguel Angel Porrúa, 2012.

75 También puede verse México Evalúa, 2012.

${ }^{76}$ Hope, art. cit. 
En la primera sección de este trabajo, definí el liderazgo político como el logro de cambios importantes a través de una actuación estratégica, de acuerdo al contexto. En función de esta definición, después de analizar el sexenio del presidente Calderón puedo concluir que no ejerció dicho liderazgo, tomando en cuenta tres elementos:

1. En un contexto que le abría la posibilidad de conseguir transformaciones significativas en múltiples materias, en el marco del "nuevo orden" que su predecesor había propuesto pero fracasado en alcanzar,

2. El presidente no logró impulsar dichas transformaciones, ya que no sólo no resolvió el problema central de su agenda, el crimen organizado, sino que lo empeoró, mientras que los cambios en otros temas fueron muy modestos (pensiones, finanzas públicas, energía, salud, democracia, trabajo, empleo y medioambiente), nulos (educación y telecomunicaciones) o incluso negativos (pobreza);

3. Lo cual se debió a dos factores: $a$ ) una agenda poco pertinente, esto es, que se concentró en un objetivo poco factible, relegando otros objetivos cuando era probable alcanzarlos y promoviéndolos (unilateralmente) cuando ya no lo era; y b) una actuación poco estratégica, especialmente en relación a la lucha contra el crimen organizado.

¿Podía Calderón haber actuado de manera diferente? Me parece que sí, en al menos dos momentos. El primero fue al principio, cuando, advertido explícitamente sobre los riesgos, pudo haber evitado colocar en el centro de su agenda un objetivo tan difícil de alcanzar, o en su caso haber implementado una estrategia más eficaz y menos costosa. El segundo momento fue a finales de 2008 y principios de 2009, cuando a) había logrado la aprobación de cinco reformas que, aunque modestas, mostraban cierta capacidad para lograr cambios con base en acuerdos, $b$ ) su popularidad estaba aún en niveles aceptables y $c$ ) era evidente que su política contra el crimen organizado no estaba mostrando resultados, pero sí muchos costos. En ese momento, podía haber cambiado la estrategia y el lugar central de esta política, defendido el récord de reformas obtenidas e impulsado en forma consensada las que aún 
estaban pendientes, utilizando por ejemplo la crisis económica y los demás problemas del país. Por supuesto, nada estaba garantizado, pero, siguiendo a Neustadt, ello al menos le hubiera abierto margen de maniobra para en la segunda parte de su sexenio promover nuevos cambios y aumentar -o al menos mantener-su capital político y el de su partido.

Sin embargo, en lugar de ello, como vimos, a principios de 2009 se obstinó en mantener la estrategia y centralidad de la "lucha" contra el crimen organizado para la que no contaba con los recursos suficientes y, peor aún, a partir de ella inició una ofensiva política contra el PRI, que hasta ese momento había sido su principal aliado. Posteriormente, cuando la derrota en las elecciones de 2009 ameritaba una agenda más limitada y un estilo más negociador, lanzó unilateralmente nuevas iniciativas, lo que le trajo derrotas anunciadas y un deterioro mayor de su capital político. Quizá pensó que, como en la lucha por la candidatura presidencial o por la presidencia misma, superaría de nuevo este difícil reto a base de arrojo y determinación, sin darse cuenta de que el contexto era ahora muy diferente. ${ }^{77}$ En síntesis, Calderón no supo escoger adecuadamente los tiempos y los ámbitos para la acción, la abstención, la resistencia y la corrección, a los que he hecho referencia en la primera sección.

Ahora bien, evaluar a los presidentes a partir de sus errores iniciales, especialmente a los que llegan al poder con poca o nula experiencia ejecutiva, podría resultar un tanto injusto. Sí se les puede criticar sin embargo por no "crecer en el puesto"; esto es, por ser incapaces de aprender de sus fallas. En Estados Unidos

${ }^{77}$ En este sentido, vale la pena recordar aquí a Maquiavelo (op. cit., pp. 85-87): "[...] en las cosas que conducen al fin al que todos aspiran, esto es, gloria y riquezas, los hombres proceden en formas diferentes: unos cautelosamente, otros impetuosamente; unos fuertemente, otros suavemente; unos pacientemente, otros impacientemente; y cada una de estas maneras de actuar puede ser efectiva [...] De dos hombres cautelosos, uno puede alcanzar sus objetivos y el otro fracasar [...] La razón para estos diferentes resultados es si la manera de actuar se adaptaba a las condiciones en las que operaban [...] Concluyo entonces que dado que las circunstancias varían $[\ldots]$ los hombres [...] son exitosos si sus métodos se adaptan a las circunstancias y fracasan cuando no lo hacen”. 
existen casos de presidentes sin experiencia ejecutiva que al principio cometieron errores, pero que aprendieron de ellos y quedaron así incluidos entre los mejor considerados de la historia de ese país, como Lincoln o Kennedy; hay otros en cambio que se obstinaron en sus desaciertos, como Franklin Pierce, quedando por ello en la lista de los peores. Aunque este es un juicio que sólo el tiempo podrá decantar, por los magros resultados obtenidos frente a la mayoría de los problemas, su pacto con "poderes fácticos" como el de Elba Esther Gordillo, pero, paradójicamente, sobre todo por haber abierto una caja de pandora y agravado el problema del crimen organizado, en estos momentos no parecería que vaya a ocupar un buen lugar en la historia de los presidentes mexicanos.

¿Qué factores pueden explicar la falta de una actuación estratégica por parte de Calderón? En las consideraciones teóricas argumenté que la actuación estratégica es facilitada o dificultada por el "estilo decisorio" del gobernante. Dije que en general tiende a suceder lo primero cuando se tiene un estilo "equilibrado", que balancea la apertura con la determinación, esto es, la capacidad para el diálogo y para reconocer errores con la firmeza en las decisiones. En contraste, es dificultada por un estilo "desequilibrado", que cae ya sea en el extremo de la discusión caótica, vacilante y negligente, o del voluntarismo cerrado, arrogante e intransigente. Conseguir el equilibrio no es fácil, pero mencioné que los gobernantes tienden a caer con más facilidad en la arrogancia (y aún más cuando sienten que son "estratégicos") ${ }^{78}$ Esto puede tener efectos negativos porque muchos de los asuntos públicos constituyen "problemas perversos", que se prestan más a estrategias de acierto-error que a decisiones irrevocables (aunque por supuesto ello tampoco quiere decir que los gobernantes deban convertirse en veletas). Con todo, como he subrayado en este texto, la dificultad del ejercicio efectivo de la presidencia surge en buena medida de que constantemente tiene que estar decidiendo los ámbitos y tiempos para la acción, la abstención, la resistencia y la corrección. Y en esta compleja tarea tanto la impulsividad de los estilos decisorios muy fuertes como la lentitud de los muy vacilantes resultan de poca ayuda.

${ }^{78}$ Pious, op. cit. 
Usualmente es difícil identificar claramente el estilo decisorio de un gobernante. En el caso de Felipe Calderón, sin embargo, no lo es tanto. Muchas y muy variadas voces han coincidido en describir su fuerte carácter, reducida modestia y profunda desconfianza. Durante su sexenio era frecuente leer u oír relatos de panistas, funcionarios de diverso nivel o ciudadanos sobre sus explosiones de enojo en las reuniones de trabajo o muestras de disgusto ante los juicios críticos. Aunque con frecuencia también se mostraba dispuesto a oír opiniones, la posibilidad de que súbitamente el presidente empezara a dar gritos o manotazos en la mesa al parecer generaba un clima de temor o ansiedad. ${ }^{79}$ Como mencioné antes, si Fox hizo muy pocos cambios en el gabinete, Calderón haría 23 (casi el mismo número que Salinas). Hacia fuera ello podía proyectar una imagen de firmeza y atención; hacia dentro provocaba tensión o zozobra, cuando no resentimiento. ${ }^{80} \mathrm{El}$ predominantemente bajo perfil de los secretarios es otro indicador de su poca disposición al cuestionamiento o discusión de sus decisiones. En la Oficina de la Presidencia, a la cual llegó el equipo compacto que lo

${ }^{79}$ Entrevista a funcionario público, México, D. F., 23 de noviembre de 2010. Ante las críticas a su "autoritarismo”, Calderón decía que él no lo era y que prueba de ello era su disposición a reunirse y oír directamente a las personas o grupos inconformes. En efecto, el presidente se reunió por ejemplo con los compañeros o familiares de las víctimas de los enfrentamientos relacionados con el crimen organizado, los padres de las familias de los niños muertos por el incendio de la guardería ABC o con Sicilia y los miembros del Movimiento por la Paz. Algunas de sus actitudes en esas reuniones, sin embargo, abrían la duda de si iba a ellas para oír a los agraviados o más bien para intentar persuadirlos o calmarlos.

${ }^{80}$ No es posible citar aquí las innumerables menciones al respecto en diversas revistas, periódicos y libros. Para algunos ejemplos pueden verse las cartas a Calderón tanto de panistas como Carlos Castillo Peraza y Javier Corral, como de integrantes de la sociedad civil como Claudio X. González Guajardo o Javier Sicilia (reproducidas en Núñez, op. cit., pp. 285-299). Puede verse también Tuckman, op. cit., 69 y 72; Julio Scherer, Calderón de cuerpo entero, México, Grijalbo, 2012, pp. 60, 89, 97, 100 y 101; y la entrevista a Vicente Fox publicada el 14 de marzo en El Universal. En varias reuniones y comidas en las que el autor estuvo presente con funcionarios de la administración de Calderón se mencionaba repetidamente la frase atribuida a Diego Fernández de Cevallos sobre que "Calderón no es de mecha corta; no tiene mecha”. Por supuesto, lo significativo no es si ésta es cierta o no, sino su frecuente repetición en dichas reuniones. 
había venido acompañando desde años atrás, impuso largos horarios y un esquema de asesoría cercano al que en otro lugar he llamado de "certidumbre cooperativa", 81 en el que las decisiones están claramente centralizadas en un chief of staff (en este caso, el Jefe de la Oficina de la Presidencia). En este sentido, quizá su estilo de toma de decisiones ofrecerá un buen ejemplo de la naturaleza y efectos del "pensamiento grupal". ${ }^{82}$ En síntesis, existen múltiples evidencias de que Calderón tuvo un estilo desequilibrado hacia la impulsividad, la arrogancia y la intransigencia.

En relación a la oposición, es muy probable que buena parte de la reticencia primero a participar en el gabinete y luego a negociar la aprobación de reformas tuviera que ver con el cálculo, como es normal en la política, pero es evidente que un estilo como este tampoco facilita la disposición a cooperar. Por ejemplo, a lo largo de su gobierno, Calderón mostró hacia al PRI una constante ambivalencia: a veces se mostraba dispuesto a acercársele y negociar, pero en otras parecía resistirse a hacerlo o de plano lo atacaba.

\section{CONCLUSIONES Y PERSPECTIVAS}

$\mathrm{Al}$ inicio de este artículo se señaló que los presidentes enfrentan un dilema: por un lado, deben ejercer un liderazgo; por el otro, éste es de naturaleza elusiva -difícil de entender y alcanzare implica tanto oportunidades como riesgos. Se argumentó que los gobernantes pueden afrontar más efectivamente dicho dilema, y los académicos y ciudadanos evaluarlos mejor, si se concibe al liderazgo como la actuación estratégica para la obtención de logros importantes dado el contexto, en lugar de en función del carisma o una "gran visión". Aparte de valorar mejor a gobernantes más "modestos", la perspectiva propuesta advierte sobre las consecuencias negativas que resultan de una percepción poco

${ }^{81}$ J. L. Méndez, "La oficina presidencial y el liderazgo político en México y Estados Unidos ¿incertidumbre competitiva o certidumbre cooperativa?”, Foro Internacional, octubre-diciembre de 2007.

${ }^{82}$ Irving L. Janis, Victims of Groupthink: A Psychological Study of Foreign-Policy Decisions and Fiascoes, Houghton Mifflin, 1972. 
estratégica del liderazgo político, especialmente cuando se persiste en objetivos excesivamente ambiciosos o en estrategias equivocadas.

En este artículo se desarrolló un análisis de la presidencia de Felipe Calderón basado en esta concepción del liderazgo como actuación estratégica. Para ello, se analizó la medida en que este presidente desarrolló un agenda pertinente, un palanqueo inclusivo y un estilo decisorio equilibrado. En función de lo expuesto, podemos concluir que no los desarrolló y que por lo tanto no ejerció un liderazgo político. De hecho, más bien hizo lo contrario: se planteó objetivos poco factibles (avanzar en la guerra contra el narcotráfico y posteriormente aprobar varias reformas estructurales), los cuales buscó realizar según estrategias inadecuadas (una ofensiva punitiva militar generalizada y una orientación predominantemente unilateral y plebiscitaria, respectivamente), por lo que terminó perdiendo cada vez mayor capital político e incluso empeorando el problema que más buscaba resolver. El presidente fue explícitamente advertido al inicio de su administración de los fuertes riesgos de una ofensiva militar, la cual además comenzó a ser fuertemente criticada a partir sobre todo de 2009. Así, el problema no fue sólo que incurrió en errores de agenda y estrategia, sino que fue incapaz de aprender de ellos para "crecer en el puesto".

En cuanto a la agenda, Calderón tuvo un contexto relativamente favorable para el liderazgo en relación a ciertos temas. Por un lado, no era un tiempo de reconstrucción porque Vicente Fox ya había propuesto un "nuevo orden" y él pertenecía al mismo partido y había desarrollado una campaña hasta cierto punto basada en la orientación del gobierno precedente. Además, su partido no tenía mayoría en el congreso. Sin embargo, las propuestas de este "nuevo orden" aún estaban por realizarse. Al inicio de su gobierno se había construido una buena reputación presidencial, tenía un nivel aceptable de aceptación popular y la construcción de mayorías legislativas estaba a su alcance para la aprobación de reformas importantes en diversos ámbitos. Pese a ello, decidió concentrar su agenda y sus energías en una "guerra contra el narcotráfico" en la cual resultaría muy difícil mostrar resultados. En función de lo anterior, podemos decir que 
no planteó una agenda pertinente para el tiempo político que enfrentaba.

Si de por sí la agenda no fue estratégica, tampoco lo sería la actuación para conseguirla. Aparte de que los recursos eran insuficientes y planteó la búsqueda de su objetivo como una "guerra", implementó una estrategia militar inadecuada y dirigida en buena medida hacia los mandos superiores de los grupos criminales, lo cual le impidió ofrecer en forma convincente avances en la reducción del narcotráfico, catalizó un fuerte aumento de la violencia y la inseguridad y le hizo perder a sus aliados en el congreso, todo lo cual erosionó crecientemente su capacidad política. En contraste, en los ámbitos donde podía haber promovido cambios relativamente ambiciosos logró apenas avances parciales (mini-reformas pensionaria, fiscal, electoral y energética), relegando por completo las demás. Todo esto -junto con una fuerte crisis económica y, en cierta medida, su lentitud para reaccionar ante una tragedia local-coadyuvó a la derrota de su partido en las elecciones intermedias para renovar la cámara de diputados, lo que le hizo perder la capacidad de iniciativa legislativa. Quiso remontar esta caída con una nueva ofensiva, curiosamente en los ámbitos que antes había relegado, lo cual lo llevó a sufrir nuevas derrotas y a perder aún más capital político. En 2012 su partido perdió la presidencia, dos gubernaturas, además de decenas de diputaciones y senadurías. Él perdió la influencia decisiva que al inicio había ganado dentro del PAN.

¿Qué factores pueden explicar su falta de actuación estratégica? En las consideraciones teóricas se planteó que uno de estos factores puede ser el estilo decisorio. Aunque a veces establecer esta conexión no es sencillo por las dificultades para identificar con claridad dicho estilo para un gobernante, en el caso de Calderón referencias de variado tipo y procedencia fundamentan la existencia de un estilo decisorio desequilibrado hacia la arrogancia, la impulsividad y el protagonismo, que probablemente estuvo en el origen de sus errores.

El 1 de diciembre de 2012, en un claro contexto de reconstrucción, llegó a la presidencia Enrique Peña Nieto. Su partido tampoco obtuvo la mayoría legislativa. Ante ello, más que plantear unilateralmente una agenda, como lo hizo Calderón, en el periodo 
de transición coadyuvó para desarrollar un "pacto por México" entre los principales partidos en torno a un amplio conjunto de propuestas. En buena medida a partir de este pacto, en los primeros años de su sexenio se aprobaron once reformas importantes, especialmente cuatro: la educativa, político-electoral, energética y de telecomunicaciones. Ellas plantearon cambios profundos en sus respectivas materias, al menos formalmente.

Por supuesto, aún no ha pasado suficiente tiempo para hacer una evaluación más fundada del grado de liderazgo político del actual presidente mexicano. Aún está por observarse cómo se dará la implementación de estas reformas (un proceso también complejo), así como sus resultados para el país. Asimismo, al momento de escribir este artículo no queda claro si el presidente está atacando en forma eficaz otros problemas, como los de la seguridad, ${ }^{83}$ la infraestructura de comunicaciones y transportes, el combate a la pobreza o el crecimiento económico, que en 2013 apenas superó el 1\%.84

Aunque la historia no tiene por qué repetirse, es de notar que al menos dos presidentes del PRI que empezaron a afrontar con éxito lo que en su época parecía un tiempo de reconstrucción (José López Portillo y Carlos Salinas) terminaron muy mal sus respectivos sexenios. De nuevo, es posible que parte de la explicación de sus fracasos haya estado en su estilo decisorio, también cargado hacia el voluntarismo, la arrogancia y el autoritarismo. En estos momentos, con todo y que ha habido una evidente recentralización institucional, la evidencia para evaluar el estilo de Peña Nieto no es totalmente clara. Habrá que ver si termina decantándose hacia el equilibrio entre la apertura y la determinación o hacia alguno de los dos desequilibrios arriba descritos. Como analistas y ciudadanos, no nos queda más que esperar lo primero.

${ }^{83} \mathrm{El}$ problema del crimen organizado y la inseguridad se había agudizado para 2014 en Michoacán, más de siete años después de que Calderón empezara ahí su ofensiva contra el narcotráfico. En estos momentos, el gobierno federal prácticamente ha tomado el control de la seguridad pública en la entidad. Está por verse cuál será el resultado.

${ }^{84}$ INEGI, "Producto Interno Bruto en México durante el cuarto trimestre de 2013”, Boletín de prensa, núm. 95/14, Instituto Nacional de Estadística y Georgrafía, 21 de febrero de 2014, http://www.inegi.org.mx/inegi/contenidos/espanol/ prensa/comunicados/pibbol.pdf 


\section{BibLiOgRAFÍA}

Abranches, Sérgio, "O presidencialismo de coalizão: o dilema institucional brasileiro", Dados, vol. 31, num. 1, 1988, pp. 5-33.

Aguilera, Sylvia, José Merino y Mara Hernández, "La esquina entre seguridad y justicia: relato de dos iniciativas y una reforma", en Mara Hernández et al. (eds.), Un congreso sin mayorías, México, Flacso-Centro de Colaboración Cívica, 2009.

Calderón, Felipe, Mensaje del Primer Informe de Gobierno, México, Presidencia de la República, 2006.

Castellanos, Roberto, Claudia Suárez y Vania Montalvo, "La reforma fiscal 2008”, en Mara Hernández et al. (eds.), Un Congreso sin mayorías: mejores prácticas en negociación y construcción de acuerdos, México, Flacso, 2009.

Condon, Bradly J. y Tapen Sinha, "The Effectiveness of Pandemic Preparations: Legal Lessons from the 2009 Influenza Epidemic”, International Federation of Red Cross and Red Crescent Societies, 2009, en http://www.ifrc.org/Global/Publications/IDRL/working-papers/ pandemic-preparedness-sept-2009.pdf

Consulta Mitofsky, "México: Evaluación Final de Gobierno Felipe Calderón: 2006-2012", 2012, http://consulta.mx/web/images/evgobierno/2013/evaluacionfinalcalderon.pdf

Cosío Villegas, Daniel, El estilo personal de gobernar, México, Grijalbo, 1972.

Ch, Rafael y Marien Rivera, "Números rojos del Sistema Penal", cidac, octubre de 2011, http:/ /www.cidac.org/esp/uploads/1/CIFRAS.pdf , "Números rojos", Nexos, febrero de 2012.

Dallek, Robert, "When Presidents Become Weak", en Walter Isaacson (ed.), Profiles in Leadership: Historians on the Elusive Quality of Greatness, Nueva York, W. W. Norton \& Company, 2010.

Elizondo, Carlos, Por eso estamos como estamos, México, Random House Mandadori, 2011.

Edwards, George, III, The Strategic President: Persuasion and Opportunity in Presidential Leadership, Princeton, Princeton University Press, 2009.

—, Presidential Leadership: Politics and Policymaking, Boston, Wadsworth, 2009.

Farfán, Gabriel y Ana Lucía García, "De la confrontación nació el acuerdo: la reforma de Petróleos Mexicanos", en Mara Hernández et al. 
(eds.), Un congreso sin mayorías, México, Flacso-Centro de Colaboración Cívica, 2009.

Goodwin, Doris Kearns, A Team of Rivals: The Political Genius of Abraham Lincoln, Nueva York, Simon \& Schuster, 2005.

Gramsci, Antonio, Notas sobre Maquiavelo, sobre politica y sobre el Estado moderno, México, Juan Pablos, 1975.

Guillén, Diana y Gabriela Melo, "La reforma del Issste", en Mara Hernández et al. (eds.), Un Congreso sin mayorias: mejores prácticas en negociación y construcción de acuerdos, México, Flacso, 2009.

Guerrero, Eduardo, "La estrategia fallida”, Nexos, diciembre de 2012. , "2011: La dispersión de la violencia”, Nexos, febrero.

, "La raíz de la violencia”, Nexos, junio de 2011.

—_, "Epidemias de violencia", Nexos, julio de 2012.

Hall, Peter, "Policy Paradigms, Social Learning and the State: The Case of Economic Policymaking in Britain”, Comparative Politics, vol. 25, núm. 3, 1993, pp. 275-296.

Hope, Alejandro, "Violencia 2007-2011. La tormenta perfecta", Nexos, noviembre de 2013.

Instituto Federal Electoral, "Las elecciones del primero de julio: cifras, datos, resultados", Instituto Federal Electoral, http://www.ife.org.mx/ docs/IFE-v2/CNCS/CNCS-IFE-Responde/2012/Julio/Le010712/ Le010712.pdf

, "LX Legislatura (2006-2012)", Integración de la Cámara de Senadores de la República Estadística de las Elecciones Federales de 2006, Instituto Federal Electoral, http://www.ife.org.mx/documentos/Estadisticas2006/senadoresrp/cam_senadores.html

INEGI (Instituto Nacional de Estadiística y Georgrafía), "Producto interno bruto trimestral”, Estadísticas Económicas, Instituto Nacional de Estadística y Geografía, 2010, http:/ / www.inegi.gob.mx/prod_serv/contenidos/espanol/bvinegi/productos/derivada/coyuntura/pib/pib.pdf -, "Boletín de prensa número 288/13. En 2012 se registraron 26 MIL 037 homicidios”, Aguascalientes, INEgi, 30 de julio de 2013. , "Producto Interno Bruto en México durante el cuarto trimestre de 2013”, Boletín de prensa, núm. 95/14, Instituto Nacional de Estadística y Georgrafía, 21 de febrero de 2014, http://www.inegi.org.mx/ inegi/contenidos/espanol/prensa/comunicados/pibbol.pdf -, Banco de Información del INEGI; número de homicidios por año. 
Janis, Irving L., Victims of Groupthink: A Psychological Study of Foreign-Policy Decisions and Fiascoes, Houghton Mifflin, 1972.

Keohane, Nannerl O., Thinking about Leadership, Princeton, Princeton University Press, 2010.

Loaeza, Soledad, "El estilo personal de Vicente Fox y los límites de la autoridad presidencial", en Soledad Loaeza, Acción Nacional. El apetito y las responsabilidades del triunfo, México, El Colegio de México, 2010.

Krauze, Enrique, La presidencia imperial, México, Tusquets, 2004.

Loyola, Rafael, "Manuel Ávila Camacho: el preámbulo del constructivismo revolucionario", en Will Fowler (coord.), Gobernantes mexicanos, México, FCE, 2008.

Loza, Nicolás, Legitimidad en disputa. Zedillo, Fox, Calderón, México, Flacso, 2008.

Maquiavelo, Nicolás, The Prince, Cambridge, Cambridge University Press, 1989.

Méndez, José Luis, "La política pública como variable dependiente: hacia un análisis más integral de las políticas públicas”, Foro Internacional, enero-marzo de 1993.

, "La Oficina de la Presidencia en los gobiernos de América Latina”, ponencia presentada en el CLAD, Santiago de Chile, 2005.

, "La oficina presidencial y el liderazgo político en México y Estados Unidos cincertidumbre competitiva o certidumbre cooperativa?", Foro Internacional, octubre-diciembre de 2007.

, "Cincuenta años de estudios sobre el liderazgo presidencial: aportaciones para la consolidación democrática a través de una presidencia estratégica en América Latina”, Buen Gobierno, núm. 10, enero-junio de 2011.

— estratégica”, en José Luis Méndez (comp.), Liderazgo político, México, Siglo XXI, 2013.

México Evalúa, Indicadores de víctimas visibles e invisibles de homicidio, México, México Evalúa, 2012.

Muñoz, Víctor, "Las políticas del sector salud en el sexenio de Felipe Calderón”, en María Eugenia Valdés (coord.), Los problemas nacionales durante el gobierno de Felipe Calderón, México, Miguel Ángel Porrúa, 2012.

Neustadt, Richard, Presidential Power and the Modern Presidents: The Politics of Leadership from Roosevelt to Reagan, Nueva York, Free Press, 1990. 
Núñez, Ernesto, Crónica de un sexenio fallido: la tragedia del calderonismo, México, Grijalbo, 2012.

Nye, Joseph, Presidential Power and the Modern Presidents: The Politics of Leadership from Roosevelt to Reagan, Nueva York, Oxford University Press, 2008.

Pious, Richard M., Why Presidents Fail, Nueva York, Rowman and Littlefield Publishers Inc., 2008.

Poiré, Alejandro, "El tercer mito: Falso que la presencia de la autoridad detone sistemáticamente la violencia”, Blog de la Presidencia de la República, publicado el 13 de junio de 2011, http://www.presidencia.gob.mx/el-blog/ el-tercer-mito-falso-que-la-presencia-de-la-autoridad-detone-sistematicamente-la-violencia/ \#more-67458

Preston, T. y M. G. Hermann, "Presidential Leadership Style and the Foreign Policy Advisory Process", en E. R.Witkopf y J. M.McCormick (eds.), The Domestic Sources of American Foreign Policy: Insights and Evidence, Landham, Rowman y Littlefield, 2004.

Reyes, Luis, "La alianza del SNTE con el gobierno de Calderón”, en María Eugenia Valdés (ed.), Los problemas nacionales durante el gobierno de Felipe Calderón, México, Miguel Ángel Porrúa, 2012.

Riker, William H., The Art of Political Manipulation, New Haven, Yale University Press, 1986.

Rockman, Bert, "When It Comes to Presidential Leadership, Accentuate the Positive but Do Not Forget the Normative", en Bert Rockman y Richard Waterman (eds.), Presidential Leadership: The Vortex of Power, Oxford, Oxford University Press, 2008.

Rotberg, Robert I., "Failed States, Collapsed States, Weak States: Causes and Indicators", en Robert I. Rotberg (ed.), State Failure and State Weakness in a Time of Terror, Cambridge, World Peace Foundation, 2003.

Sánchez, Abraham, "Análisis de las reformas educativas de la educación básica del periodo 200-2012”, en Miguel Ángel Vértiz (coord.), Estudios sobre reformas educativas, México, Universidad Pedagógica Nacional, 2013.

Scherer, Julio, Calderón de cuerpo entero, México, Grijalbo, 2012.

Secretariado Ejecutivo del Sistema Nacional de Seguridad Pública, "Tasa por cada 100 mil habitantes", Incidencia delictiva, 16 de abril de 2014, http:/ / www.secretariadoejecutivosnsp.gob.mx/es/SecretariadoEje cutivo/090820132 
Skowronek, Stephen, The Politics Presidents Make: Leadership from John Adams to Bill Clinton, Cambridge, Harvard University, 1998.

Trejo, Guillermo, "Violencia y política en el México del bicentenario", en Rolando Cordera (coord.), Presente y perspectivas, México, cIDE/ FGe/Conaculta/IneHrm/Fundación Cultural de la Ciudad de México, 2010.

Tronco, José del, “¿El fin justifica los medios? Deliberación y negociación de la reforma electoral 2007”, en Mara Hernández et al. (eds.), Un Congreso sin mayorias: mejores prácticas en negociación y construcción de acuerdos, México, Flacso, 2009.

Tuckman, Jo, Mexico: Democracy Interrupted, New Haven, Yale University Press, 2012.

Valdés, María Eugenia, "El gobierno de Felipe Calderón en el sector de la radiodifusion y las telecomunicaciones", en María Eugenia Valdés (coord.), Los problemas nacionales durante el gobierno de Felipe Calderón, México, Miguel Ángel Porrúa, 2012.

Valverde, Miguel Ángel y Mary E. Hilderbrand (eds.), Transformación, lo mismo de siempre o progreso lento y con tropiezos; reformas recientes al sector público en México, México, Miguel Ángel Porrúa, 2012. 